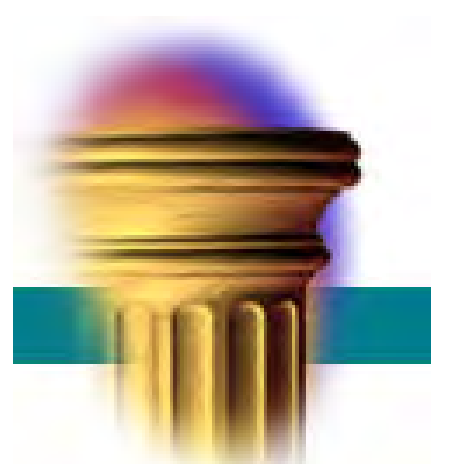

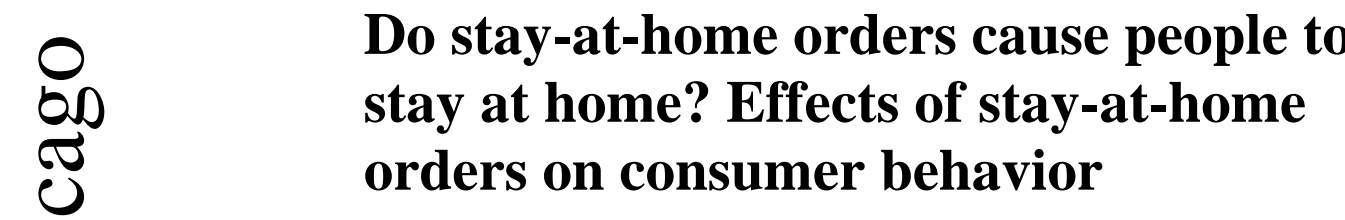

Diane Alexander and Ezra Karger

\author{
REVISED \\ August 19, 2021
}

WP 2020-12

https://doi.org/10.21033/wp-2020-12

${ }^{*}$ Working papers are not edited, and all opinions and errors are the responsibility of the author(s). The views expressed do not necessarily reflect the views of the Federal Reserve Bank of Chicago or the Federal Reserve System. 


\section{Do stay-at-home orders cause people to stay at home? Effects of stay-at-home orders on consumer behavior}

\author{
Diane Alexander* \\ The Wharton School \\ University of Pennsylvania
}

\author{
Ezra Karger ${ }^{\dagger}$ \\ Federal Reserve Bank \\ of Chicago
}

August 19, 2021

We link the county-level rollout of stay-at-home orders during the Covid-19 pandemic to anonymized cell phone records and consumer spending data. We document three patterns. First, stay-at-home orders caused people to stay home: county-level measures of mobility declined 6-7\% within two days of when the stayat-home order went into effect. Second, stay-at-home orders caused large reductions in spending in sectors associated with mobility: small businesses and large retail chains. Third, we estimate fairly uniform responses to stay-at-home orders across the country; effects do not vary by county-level income, political leanings, or urban/rural status.

JEL Codes: E21, I12, R2, R5

Keywords: Covid-19, stay-at-home orders, consumer spending, high-frequency data

*dealexa@wharton.upenn.edu; 3641 Locust Walk, Colonial Penn Center, Philadelphia, PA 19104.

${ }^{\dagger}$ karger@uchicago.edu; 230 South LaSalle Street, Chicago, IL 60604.

First version posted April 17th, 2020. We thank Womply, Second Measure, and Unacast for providing us with access to their proprietary data for use in this paper. We also thank Aastha Rajan and Amanda McFarland for outstanding research assistance. Any views expressed in this paper do not necessarily reflect those of the Federal Reserve Bank of Chicago or the Federal Reserve System. All errors are our own. 
During the Covid-19 pandemic, many cities, counties, and states requested or required that their residents stay at home. These "stay-at-home" orders restricted people from leaving their homes for anything other than essential activities. ${ }^{1}$ Policymakers assumed that stay-at-home orders would reduce social interactions, and therefore slow the spread of Covid-19. But some areas resisted implementing stay-at-home orders, citing the potential damage to small businesses and local economies.

In this paper, we use county-day variation in stay-at-home orders and an event study framework to examine the causal effect of these orders on consumer behavior. We link a county-day panel of stay-athome orders to county-day measures of mobility from Unacast's cellphone location data and consumer spending at small and large businesses from Womply and Second Measure (respectively). The consumer spending panels are available at the county-day (Womply) and state-day (Second Measure) level, and can be disaggregated by industry, which allows us to compare the effect of stay-at-home orders on spending at different types of businesses. As the mobility and small business data are available at the county level, we are also able to explore heterogeneity by local characteristics.

Using an event study framework, we find that stay-at-home orders immediately caused consumers to travel less and reduce spending in sectors associated with mobility and social interactions. Within two days of when counties enacted a stay-at-home order, people traveled $6 \%$ less than they did before the order, and made 7\% fewer visits to non-essential businesses. Stay-at-home orders also decreased consumer spending by $16 \%$ at small businesses and $13 \%$ at large retail chains within two days of the orders' implementation. While our estimates are not reflective of aggregate (general equilibrium) effects, the immediate effects of stay-at-home orders are nevertheless policy-relevant parameters for individual counties and states making short-run decisions about how to respond to pandemics.

Strikingly, we estimate nearly identical effects of stay-at-home orders on local mobility and small business revenue across different types of counties (for example, by political leanings and by income). Although because of limited precision, we cannot reject the possibility of some differences. These findings suggest that the orders were broadly effective, even in areas where they were less popular, which has important policy implications for governmental responses to future Covid-19 outbreaks or other pandemics. We show

\footnotetext{
${ }^{1}$ Most states still allowed residents to leave their homes to shop for groceries and other essential goods and services, to exercise outdoors, and to use healthcare services, though each state or locality's order was slightly different.
} 
that policymakers responding to pandemics can accomplish their overarching goal of reducing physical interactions in high-income, low-income, rural, urban, Democrat-supporting, and Republican-supporting areas of the United States. However, this change in behavior also comes with a substantial economic cost; stay-at-home orders cause sizable declines in spending at retail stores and small businesses.

While stay-at-home orders caused large changes in consumer behavior, these effects explain only part of the dramatic changes in household spending towards the end of March 2020 (see for example Bachas et al. (2020), Baker et al. (2020), Bartik et al. (2020), Carvalho et al. (2020), Goolsbee and Syverson (2021), and Lewis, Mertens, and Stock (2020)). We show that stay-at-home orders explain a fifth of the decline in mobility and between a quarter and a half of the decline in small business revenue during this time period. One potential explanation for this finding is the wide variety of other policies used in many states and localities to increase social distancing, such as closing schools and non-essential businesses. For more details on other types of interventions, see Gupta et al. (2020), who compare and contrast the effects of different types of non-pharmaceutical interventions on mobility. Consumers also changed their behavior in response to Covid-19 itself, independent of local policies.

Our paper has three important strengths relative to preexisting work. First, we use a county-day level panel, detailed mobility and consumer spending data, and an event study design to precisely and comprehensively measure the immediate causal effect of stay-at-home orders on consumer behavior. Our paper is one of the first to simultaneously measure and contrast the causal effects of local stay-at-home orders on both mobility and spending, distinguishing these effects from aggregate preexisting trends. Second, as our two sources of data on consumer spending span both large and small businesses, we provide the first evidence of the effect of stay-at-home orders on spending across the firm size distribution. Third, we are the first paper to use county-level stay-at-home orders to examine heterogeneity in how mobility and consumer spending responded to stay-at-home orders at a granular geographic level.

In the interest of brevity, we touch on only the most relevant papers in a large literature studying the Covid-19 pandemic. Most of the papers in this literature focus only on mobility outcomes. Fang, Wang, and Yang (2020) show that the lockdown of Wuhan and social distancing in other cities successfully reduced inflows of people into Wuhan and outflows of people away from Wuhan. Their paper provides some of the earliest evidence that governments can successfully encourage pandemic-related social distancing. For 
additional examples of how stay-at-home orders affect mobility, see Brodeur, Grigoryeva, and Kattan (2020), Brzezinski et al. (2020), Engle, Stromme, and Zhou (2020), Goolsbee and Syverson (2021), and Wright et al. (2020) in the United States, and Ajzenman, Cavalcanti, and Da Mata (2020) in Brazil.

Our analysis goes a step beyond mobility, documenting the link between stay-at-home orders and business revenue. Mobility may seem like a good proxy of economic activity, and some prior work interprets changes in visits to businesses as changes in economic activity. However, this interpretation requires the strong assumption that there were no changes in the size of the average transaction as Covid-19 spread. We observe real economic activity, so we can directly measure the effect of stay-at-home orders on consumer spending. We find consistent negative effects of stay-at-home orders on real economic activity at small businesses and retail stores, and these effects tend to be somewhat larger than the effects of stay-at-home orders on mobility — suggesting both an intensive and extensive margin response. Our focus on consumer spending complements recent work tracking consumer spending changes in response to the Covid-19 pandemic and stay-at-home orders in Spain (Carvalho et al., 2020) and Denmark (Andersen et al., 2020).

In other important exceptions to the literature's focus on mobility, Baek et al. (2020) show that stayat-home orders increase unemployment insurance claims in affected states. Coibion, Gorodnichenko, and Weber (2020) use data from a nationally representative dataset to show that stay-at-home orders cause a reduction in mobility and spending, and change respondents' macroeconomic expectations. And Chetty et al. (2020) measure aggregate changes in mobility and spending during the Covid-19 pandemic. However, these papers focus on aggregate trends and average causal effects, and only briefly discuss heterogeneity.

Another small literature explores heterogeneity in consumer responses to Covid-19. For example, Allcott et al. (2020) and Barrios and Hochberg (2020) show that political beliefs strongly predict rates of social distancing during the pandemic. Painter and Qiu (2020) measure the effect of state-level stay-at-home orders on mobility and spending, but find muted effects of stay-at-home orders on both outcomes-perhaps because of their use of state-level variation. They also show that democratic counties respond slightly more than republican counties to these state-level stay-at-home orders. We examine this source of heterogeneity using more comprehensive county-level variation in stay-at-home orders, and find minimal partisan-based differences in the effect of stay-at-home orders on consumer behavior. 


\section{Data}

We use four sources of data to document how stay-at-home orders affect consumer behavior. First, we construct a new dataset of county-day level stay-at-home orders covering the first phase of the Covid19 pandemic in the United States (March 1st to April 17th). Second, to quantify mobility, we use two measures based on cell phone location data from Unacast: average distance traveled and visits to nonessential businesses (Unacast 2020). Finally, to measure consumer spending we use two data sources: revenue at small businesses from Womply, and spending at large businesses from Second Measure. We supplement these four datasets with county-level characteristics to examine heterogeneity in consumers' responses to stay-at-home orders.

We hand-collect stay-at-home orders for each county in the United States, focusing on the date when the order went into effect. ${ }^{2,3}$ Although the content of stay-at-home orders varies across places, most orders follow a simple formula: residents are asked not to leave their homes, with exceptions for essential trips (such as those related to healthcare, grocery stores, or work at essential jobs). ${ }^{4}$ Cities, counties, and states issued stay-at-home orders. In cases where a city imposed a stay-at-home order, we map that city to the county (or counties) containing the city. Including city-level stay-at-home orders is a strength of our paper relative to previous work (eg. Gupta et al. (2020)); this additional data collection effort results in 43 additional counties covered by an order before a state-level order, as well as within-state timing variation in states such as Oklahoma, where only cities, rather than counties, implemented stay-at-home orders.

In Figure 1, we show that 45 states and Washington, D.C. had a stay-at-home order active in at least one county-day from March 1st to April 17th (2,642 counties were covered by a stay-at-home order over our sample period). Five states never implemented stay-at-home orders and contain no counties that implemented their own orders. In 26 states, a state-wide order was imposed before any individual counties

\footnotetext{
${ }^{2}$ The starting point for this data collection effort was the article "See Which States and Cities Have Told Residents to Stay at Home" (NYTimes, 2020a), which tracked orders across the US. We verified the accuracy of the data in the article by cross-referencing dates with those in each individual order, and supplemented the data with missing orders from state websites to construct a complete county-day level panel.

${ }^{3}$ Some counties or states announced stay-at-home orders 1-2 days before the order went into effect. However, the bulk of the response came when the order went into effect, rather than on the date of announcement.

${ }^{4}$ For an example, see San Francisco's March 16th, 2020 stay-at-home order at: https://web.archive.org/web/20200316210320/https://sf.gov/stay-home-except-essential-needs.
} 
implemented stay-at-home orders on their own - in these states (and Washington, D.C.), there is no withinstate variation in the timing of orders. However, in 19 states (including Texas, Pennsylvania, and Florida), there is significant within-state variation in the effective date of county-level stay-at-home orders. The first stay-at-home order in the United States was implemented by seven counties in the San Francisco Bay Area on March 17th, 2020; the last order in our data is a state-wide stay-at-home order implemented by South Carolina on April 7th, 2020..$^{5}$ As of April 17th, 2020, 96\% of U.S. residents were living under some form of stay-at-home order. ${ }^{6}$

To add context to the stay-at-home orders, we link our county-day panel of stay-at-home orders to county-day totals of Covid-19 cases and deaths collected by the New York Times. ${ }^{7}$ There is significant variation in the distribution of cases and deaths by timing of stay-at-home order, which reflects the fact that stay-at-home orders are an endogenous response to Covid-19 cases. In counties with an early order, cases and deaths grew significantly faster than in counties with later orders (see Figure A1). This may reflect differences in testing, as well as the fact that the counties hardest-hit by Covid-19 responded more quickly.

To measure the effect of stay-at-home orders on mobility, we use data from Unacast. Unacast uses location data from smartphones to produce two daily measures of mobility at the county-level: (1) average distance traveled and (2) visits to non-essential businesses. Unacast reports these metrics as percent differences relative to pre-pandemic levels. Unacast's mobility measures were unchanged across the United States from early 2020 until March 11th. Between March 11th and March 17th, distance traveled and visits to non-essential businesses dropped nationwide by $8 \%$ and $7 \%$ respectively. This drop preceded the first stay-at-home order in the United States and likely reflects national changes in awareness about Covid-19, such as the National Basketball Association suspending its season on March 11th. From March 17th to April 17 th, distance traveled and visits to non-essential businesses fell an additional $24 \%$ and $40 \%$ respectively from nationwide pre-pandemic levels (see Figure A2). For more details on the underlying data, the construction of the mobility measures, and the representativeness of the Unacast panel, see our Data Appendix.

To measure spending at small businesses, we use data on consumer spending from Womply. Womply provides software and tools to more than 500,000 small businesses in the United States, and then collects

\footnotetext{
${ }^{5}$ For more details about the timing of the first stay-at-home orders, see NYTimes (2020b).

${ }^{6}$ Authors' calculation using 2018 county-level population estimates from the Census Bureau.

${ }^{7}$ The New York Times shares the data on Github here: https://github.com/nytimes/covid-19-data.
} 
credit and debit card transactions directly from the payment processors used by these small businesses. Womply creates a daily time series from these transactions, aggregated to the county-sector level. In Figure A2, we show the evolution of total non-cash revenue at businesses tracked by Womply from March 1, 2020 to the present. While Womply's panel does not include all consumer spending, it provides a high frequency, real time measure of consumer spending at a large set of small businesses in 2020. For more details about the Womply panel, see our Data Appendix.

For the purposes of our analysis, we divide the Womply spending data into two types of business: those related to consumption of food and drink outside the household (including bars, sit-down restaurants, fast food businesses, small grocery stores and food shops, and delis) which we call restaurants for ease of exposition, and non-restaurant businesses (auto services, pharmacies, etc.). We separate out restaurants for some analyses because they are among the businesses most heavily hit by Covid-19. ${ }^{8}$ We divide these daily time series of aggregate county-sector level revenue by the number of establishments in each county-sector in the first week of March to construct a measure of per-establishment revenue. The average county reports $\$ 317,952$ per day of revenue in the Womply panel, with $\$ 55,416$ (17\%) coming from our aggregated restaurant category. The average establishment in Womply's panel reports daily revenue of $\$ 2,996$. Restaurants earn slightly less revenue per establishment on the average day: $\$ 1,601$ to $\$ 2,316$ depending on the type of restaurant; non-restaurant small businesses earn more per establishment on average. ${ }^{9}$ In Figure A6, we show the evolution over time of mobility and small business revenue, by timing of stay-at-home order.

To get a more complete picture of consumer spending, we supplement the data on small business revenue with data on consumer spending at large firms from Second Measure. Second Measure tracks a panel of over 4.1 million consumers' credit card, debit card, and bank transaction data. It aggregates and standardizes this transaction-level data, and produces daily state-level time series describing how much money its panel of consumers spends at 3,600 firms operating in 2019-2020. In the Second Measure data we can see the total

\footnotetext{
${ }^{8}$ See, for example, Womply's blogpost about how different sets of small businesses were affected by Covid19: https://www.womply.com/blog/data-dashboard-how-coronavirus-covid-19-is-impacting-local-business-revenueacross-the-u-s/.

${ }^{9}$ For example, the average auto sales business earns revenue of $\$ 6,154$ daily. In Table A1, we list the sub-categories of businesses in Womply's data, the average amount of daily revenue (across counties) at businesses in that subcategory during the first week of March 2020, and the aggregated category we use in our analyses (restaurant or other spending). Table A2 replicates this information, but on a per-establishment basis, weighted by county-level population.
} 
amount of money spent by Second Measure's panel of consumers at large firms like Amazon.com, Walmart, Whole Foods, Nike, and Costco. On average, consumers in Second Measure's panel (roughly 1\% of U.S. consumers) spend $\$ 64.68$ each day on firms tracked by Second Measure. ${ }^{10}$ Of that spending, $\$ 28.18$ comes from firms in the retail sector, examples of which are Walmart, Costco, and Amazon.com (see Tables A3 and A4 for summary statistics on state-level and consumer-level spending in the Second Measure data). We divide the revenue totals by the number of consumers in the panel during the first week of March to produce per consumer estimates at the state level. We separate the Second Measure data by industry, and focus on four mutually exclusive categorizations: retail, non-retail, food delivery, and Amazon.com, which make up $43.6 \%, 49.7 \%, 1.7 \%$, and $5.0 \%$ of spending, respectively. ${ }^{11}$

While Covid-19 caused large overall reductions in consumer spending at small businesses of all types, this was not true for large businesses. Overall spending at Womply's panel of small businesses fell by 37\% year-over-year as of April 17th, but spending at the larger firms in Second Measure's panel actually rose by $9 \%$ year-over-year over the same period. However, this aggregate number masks considerable heterogeneity by industry. Spending at brick-and-mortar stores in Second Measure's panel fell, but by much less than the small businesses: by $9 \%$ year-over-year. Meanwhile, online spending at large firms surged, increasing by $80 \%$ year-over-year. ${ }^{12}$ Spending on food delivery services and Amazon.com also dramatically increased, by $149 \%$ and $73 \%$ respectively. In Figure A2, we plot aggregate changes in consumer spending over time (by industry) using data from Womply and Second Measure. While the data from Womply and Second Measure are not necessarily entirely mutually exclusive, they broadly cover different portions of the economy. Throughout the paper we refer to the Womply data as covering small businesses, and the Second Measure data as covering large businesses.

Finally, we collect a series of county-level characteristics describing population, income, and urban-

\footnotetext{
${ }^{10}$ We calculate per-consumer spending in the Second Measure data by dividing total spending at tracked firms on an average day in the first week of March, 2020 by the total number of visits at firms tracked by Second Measure on that day. So if a consumer visited two different stores in Second Measure's panel, they will be double-counted in our summary statistics. This affects the levels, but not the trends, of our Second Measure data because we hold the number of 'consumers' fixed throughout our time series.

${ }^{11}$ To avoid double-counting, we remove Amazon.com from the retail sector.

${ }^{12}$ Second Measure only classifies sales as being online versus brick-and-mortar for a smaller set of companies in their coverage list, so this overall percentage does not indicate the fraction of online sales for a specific company or for their entire sample of firms.
} 
rural status from the United States Department of Agriculture (USDA). The USDA sources these summary statistics from the Bureau of Labor Statistics, the U.S. Census Bureau, and American Community Survey 2014-2018 summary tables. We also collect data on which counties voted Republican in the 2016 presidential election. ${ }^{13}$ We use this information to split our sample of counties by type in our analysis of heterogeneity in the effects of stay-at-home orders on consumer behavior: high- versus low-income and Republican-supporting versus Democrat-supporting. We define high-income (low-income) counties as those with median household income above (below) the median for counties in our sample. We designate a county Republican- or Democrat-supporting by the party of the 2016 presidential nominee supported by the county.

\section{Empirical strategy}

Our goal is to measure the immediate causal effect of stay-at-home orders on consumer behavior. We use an event study framework to compare mobility and spending patterns immediately before and after counties implement stay-at-home orders. Our analysis sample is all counties that were ever covered by a stay-at-home order from March 1st to April 17th.

Our main specification is:

$$
Y_{c, t}=\sum_{s=-10}^{10} \beta_{s} 1(\text { event occurred })_{c, t-s}+\lambda_{c}+\lambda_{t}+\varepsilon_{c, t}
$$

In our county-level analysis, $Y_{c, t}$ is one of the following outcomes:

(1) Percentage change in distance traveled (distance) or visits to non-essential businesses (visits) relative to pre-pandemic levels

(2) Logged per-establishment daily revenue of small businesses of different types

In this model, $\lambda_{c}$ and $\lambda_{t}$ are county and date fixed effects. The coefficients of interest, $\beta_{s}$, represent days-since-event fixed effects for the 10 days before and after the event. The indicator variable

\footnotetext{
${ }^{13}$ We gather this data from work done by Tony Mcgovern to collect vote margins at the county-level for U.S. presidential elections from 2008-2016. See documentation here for more details:

https://github.com/tonmcg/US_County_Level_Election_Results_08-16 This data was initially scraped from Townhall.com.
} 
1 (event occurred $)_{c, t-s}$ is 1 if the event occurred in county $c$ as of time $t-s$ and 0 otherwise. We populationweight all regressions using county-level population to ensure that our results are not being driven by noisy changes in consumer behavior in small counties, where data coverage may be poor. In our county-level event studies we also include cases and deaths (in levels and logs) as controls. ${ }^{14}$ We cluster all standard errors two-way at the state and date level. This two-way clustering allows for arbitrary correlation of errors within a state and simultaneously allows for arbitrary correlation of errors across the United States on a given day of the year. We also present our main event studies using a new method from Callaway and Sant'Anna (2020) to address concerns about the interpretation of event study coefficients in settings with staggered treatment rollout. Our results are robust to the use of this new method.

Our identifying assumption is that the exact timing of stay-at-home orders is unrelated to other timevarying policies that affected consumer behavior during this time period. We have analyzed the text and surrounding news coverage of dozens of stay-at-home orders and we are reassured that stay-at-home orders are not typically bundled with other time-varying policies (like place-level mask mandates). Although our identifying assumption is untestable, counties and states implemented stay-at-home orders as individual policies, and our event studies show sharp changes in consumer behavior in the two days following a stayat-home order. Thus, we believe that our identifying assumption likely holds.

In our event studies, we analyze changes in consumer behavior around two distinct events: the first date of a stay-at-home order, and the first date when a Covid-19 death was reported in the county. The date of a county's first death can be thought of as a placebo event, which could cause large changes in consumer behavior if local journalists or social media posts focused on this event, increasing fear of Covid-19 and changing consumer behavior. In practice, however, consumer behavior is unchanged around the date of first death, suggesting this event is likely not that salient to local residents. In all specifications, we define $s=1$ to be the first day for which the county had the relevant event. In our event-time plots, the omitted event time fixed effect is $s=-5$; this helps us more easily visualize any potential anticipation effects in the days leading up to the stay-at-home orders. ${ }^{15}$

\footnotetext{
${ }^{14}$ Results are robust to excluding these controls.

${ }^{15}$ Another option for an "alternative event" is the date a county crossed a particular case-to-population ratio threshold. In practice, however, the figures look very similar across these two types of alternative events. One potential explanation is that local measures of disease severity were not very salient early on in the pandemic, as much of the
} 
Our final sample for the county-level event studies includes every county-by-day observation in our data post-March 1st. This allows us to use counties that implemented later stay-at-home orders to help pin down the date fixed effects during the early time period. We bin the endpoints of our event-time window, so that any county-by-day observation 11 or more days before (after) the stay-at-home order went into effect has an event-time value of -11 (11).

We perform similar event studies at the state level using data from Second Measure. These event studies rely on the same empirical model, but with state and date fixed effects, and estimate the same coefficients of interest: $\left(\beta_{s}\right)$. In the state-level event studies, we define the "event" as the first date when at least half of a state's population was covered by a stay-at-home order. ${ }^{16}$

\section{Results}

Stay-at-home orders cause a sharp decline in consumer mobility and small business revenue. In Figure 2, we plot the event time coefficients from eight regressions: in blue, we show the effect of a county instituting a stay-at-home order on our main outcome measures. In red, we plot the equivalent event study estimate around the date of a county's first Covid-19-related death (our "comparison event"). In the top row of Figure 2, we find sharp decreases of 6-7\% in distance traveled and the probability a person visits a non-essential business within two days after a stay-at-home order was imposed. We find a similar pattern for restaurant revenue and other small business revenue. Stay-at-home orders reduced per-establishment revenue at both restaurant and non-restaurant small businesses in the Womply panel by $17 \%$ within two days of the stay-athome order, respectively. ${ }^{17}$ For no outcome is there evidence of a discontinuity in mobility or small business revenue around a county's first Covid-19 death.

The event studies in Figure 2 show little evidence of clear pre-trends in mobility and small business revenue. After controlling for county and date fixed effects, restaurant revenue is largely flat in the ten days leading up to the stay-at-home order, with some evidence of a small anticipation effect in the day before

disease coverage focused on national hotspots.

${ }^{16}$ In our state-level event studies we only examine the stay-at-home order event because in most places, the date of the first death in each state was even less salient.

${ }^{17}$ In Figure A12, we show the sharp overall drop in consumer spending at small businesses in Womply's panel, across all sectors. This drop of $12 \%$ persists for ten days after the effective date of the order. 
the order went into effect. For mobility, we do see some evidence of a small decline in distance traveled and visits to non-essential businesses from ten to five days before the order, but the mobility outcomes then stabilize in the five days preceding the stay-at-home order. After the stay-at-home orders come into effect, we see little evidence of a rebound in mobility, but some rebound in spending at small businesses, in particular for restaurants. Still, ten days after the stay-at-home order went into effect, small business revenue remained 10-20\% below pre-order levels. ${ }^{18}$ In Figure A3, we present our main event studies using the method of Callaway and Sant'Anna (2020), which is designed to identify average treatment effects on treated units in staggered rollout designs when there is heterogeneity in treatment effects. Their method works by only comparing treated units to never-treated or not-yet-treated units. Using this new method, we find quite similar immediate drops in mobility and small business revenue average effects, but now with no pre-trends. ${ }^{19}$

For large businesses, the sector hardest hit by stay-at-home orders is retail. In Figure 3, we perform analogous event studies at the state-level for four mutually exclusive groupings of firms from Second Measure's panel of 3,600 larger firms. ${ }^{20}$ Spending on firms in the retail sector decreases by $13 \%$ within two days of when the order went into effect before rebounding slightly. This decrease is relative to the daily average consumer spending of $\$ 28.18$ at large retail chains in our sample during the first week of March. Conversely, spending on food delivery services accelerates in the days immediately following a stay-athome order, though with some evidence of a pre-trend. And spending on non-retail businesses was largely unaffected by the orders. Finally, while spending at Amazon.com has surged during the Covid-19 pandemic, it is not caused by stay-at-home orders. We see a steady increase in spending on Amazon.com in the days immediately following a stay-at-home order, but no evidence of a trend break. ${ }^{21}$

\footnotetext{
${ }^{18}$ Our main pattern of results in Figures 2 and 3 are robust to including state-by-date fixed effects, the inclusion of which controls nonparametrically for state-level trends over time in mobility and spending. However, this specification is under-powered, as we can only examine effects in counties in states where state-level orders were preceded by local orders (See Figure A11).

${ }^{19}$ In the top left of each figure we report the average treatment effect on the treated, comparing the pre- and postevent periods.

${ }^{20}$ In Figure A13, we show the overall effect of stay-at-home orders at the state-level on consumer spending at large businesses.

${ }^{21}$ Some sectors within the non-retail category that were directly affected by Covid-19, such as transportation and hotel booking, do display strong pre-trends, with no evidence of a discontinuity caused by stay-at-home orders (Figure A8).
} 
Figure A4 presents analogous figures of the effects of stay-at-home orders on large businesses using the method of Callaway and Sant'Anna (2020). Using this method, we again find similar results: negative effects of stay-at-home orders on retail spending at large businesses and no effect of stay-at-home orders on non-retail spending at large businesses. As expected given the pre-trends evident for food delivery and Amazon.com spending in Figure 3, the effect of stay-at-home orders on food delivery spending is positive but noisy, and there is no effect of stay-at-home orders on Amazon.com spending.

In sharp contrast to the effects of stay-at-home orders on small restaurants in the Womply data, there does not seem to be any effect of the stay-at-home orders on spending at the large restaurant chains in the Second Measure data. In Figure A8 (bottom left panel), we separate out the large chain restaurants included in the Second Measure data using NAICS codes for full-service restaurants, limited-service restaurants, and cafeterias, grill buffets, and buffets. ${ }^{22}$ This null result likely reflects a drop-off in in-person dining that is made up for by an increase in drive-thru, delivery, and take-out at large chain restaurants.

\section{County-level heterogeneity}

In Figure 4, we look at how the effects of stay-at-home orders vary along three dimensions: counties with above-median or below-median household income, Republican-supporting or Democrat-supporting counties in the 2016 presidential election, and counties that implemented stay-at-home orders early (before March 27th) or later. ${ }^{23}$ We calculate these event-time coefficients by interacting the $\beta_{s}$ terms from our main equation with indicators for the type of heterogeneity in the panel heading. We then plot the event-time coefficients for each type of heterogeneity.

Consumer responses to stay-at-home orders appear similar across counties that differ by income and political leanings. For brevity, we focus on distance traveled and overall small business revenue in Figure $4 .{ }^{24}$ In low-income and high-income counties, people respond similarly to stay-at-home orders, and we find

\footnotetext{
${ }^{22}$ Examples include McDonald's, Starbucks, Chick-Fil-A, Dunkin Donuts, Taco Bell, Wendy's, Burger King, Chipotle, Panera, Domino's, Popeye's, Panda Express, Whataburger, Jack in the Box, KFC, Arby's, Pizza Hut, and IHOP.

${ }^{23}$ In Figure A5, we show the distribution of stay-at-home order timing by these three cuts of the data.

${ }^{24}$ High and low-income counties and Republican-supporting and Democrat-supporting counties also do not vary significantly in the change in average spending on non-restaurant small businesses in the days surrounding the stay-athome order (Figure A9).
} 
similar patterns when we split the data by 2016 vote share. For example, residents of Republican-supporting and Democrat-supporting counties each reduced distance traveled by $5 \%$ in the two days following a stayat-home order. The confidence intervals on our individual coefficients for each day-since-event dummy variable make it impossible for us to reject some difference in consumer responses across these groups of counties. But the very similar coefficients across counties of different types tell a suggestive story about the lack of heterogeneity.

On the other hand, the timing of the order may matter. Later orders caused smaller absolute changes in county-level distance traveled and small business revenue compared to earlier stay-at-home orders, though the difference is imprecise. A potential explanation for this pattern is that some marginal consumers already voluntarily reduced their mobility and small business spending by the time the late stay-at-home orders came into effect. This mechanism-and the fact that state-level orders were generally implemented after county-level orders - may explain why some papers looking at the effects of state-level stay-at-home orders tend to find smaller effects than we do.

One potential confounder for interpreting the splits by county characteristics in Figure 4 is that on average, Republican-supporting counties implemented stay-at-home orders later in the sample period than Democrat-supporting counties. In Figure A10, we present figures showing event studies for Republicansupporting versus Democrat-supporting counties, where we also divide counties by early versus late stayat-home orders. This figure shows that Democrat-leaning counties respond similarly to Republican leaning counties which implemented orders earlier in the period; however, for some outcomes Republican counties which implemented late stay-at-home orders appear to respond less.

In order to more formally evaluate these sources of heterogeneity, we calculate three county-level measures of changes in consumer behavior in the days surrounding a stay-at-home order: the change in distance traveled, small business revenue, and restaurant revenue in the days immediately surrounding the stay-athome order: from $s=0$ to $s=2$.

In the three panels of Table 1, we separately regress these three measures on indicators for whether a county is above-median income, Republican-supporting, or rural. In the last column, we include all three of of these variables as predictors of the immediate impact of stay-at-home orders. ${ }^{25} \mathrm{In}$ all models, we include

\footnotetext{
${ }^{25}$ The results do not differ when we bin predictors into four quantiles instead of two.
} 
date fixed effects to control nonparametrically for national changes in consumer behavior.

Table 1 confirms the visual evidence of Figure 4: we estimate that consumers in counties of different types do not respond differently to stay-at-home orders. In the top panel, we see that the three predictors have no effect on the change in distance traveled surrounding the stay-at-home order. In the middle panel, we see similar null effects of our three predictors on the change in small business revenue surrounding the order. And in the bottom panel, we see more precise null effects of income, political persuasion, and rurality on the change in small business restaurant revenue surrounding the stay-at-home orders. ${ }^{26}$ For all outcomes, all the point estimates on the county characteristics are both small in magnitude and not statistically distinguishable from zero.

\section{Conclusion}

As the Covid-19 pandemic spread across the world, stay-at-home orders emerged as one of the most widespread policies employed by local governments to encourage social distancing. Given the threats posed by Covid-19 variants and future pandemics, it is important to understand how these orders affect consumer behavior (Kissler et al. 2020; NYTimes 2020c).

We find that stay-at-home orders caused meaningful drops in mobility, as well as small business revenue, restaurant, and retail spending. However, most of the change in consumer behavior during the Covid19 pandemic cannot be attributed to the effects of these policies. By mid-April, visits to non-essential businesses fell by $51 \%$ relative to pre-pandemic levels, total distance traveled fell by $33 \%$, and sales at restaurant and non-restaurant small businesses fell by 37\% (Figure A2). We find that stay-at-home orders caused an immediate $6-7 \%$ reduction in mobility and a $16 \%$ reduction in small business revenue, with restaurant spending recovering noticeably by 5 days after the order to around $8 \%$ (Figure 2). Thus, stay-athome orders explained 15 to $20 \%$ of the decline in mobility, a quarter of the drop in small business restaurant revenue, and half of the drop in non-restaurant small business revenue during this time period.

As we move into the second year of the Covid-19 pandemic, pandemic fatigue and protests of stay-athome orders, mask mandates, and other Covid-19-related policies have become increasingly common. In

\footnotetext{
${ }^{26}$ These results are also robust to controlling for case counts the day before the stay-at-home order went into effect.
} 
the United States, many such protests have been linked to Republican-supporting organizations (NYTimes 2020d). These protests raise the question of whether stay-at-home orders can affect consumer behavior in more rural and conservative areas, which tend to push back against such restrictions. However, our results show not only that stay-at-home orders causally decreased mobility, but also that this response does not depend on county characteristics. Our findings suggest that stay-at-home orders are an effective policy tool for reducing social interactions, even in more rural and conservative areas where the policies are unpopular. Furthermore, because these conservative and rural areas were not voluntarily reducing mobility as much before the implementation of stay-at-home orders, the orders may be a particularly important part of a public health policy response in these areas. 


\section{References}

[1] Daniel Aaronson, Scott A. Brave, R. Andrew Butters, and Michael Fogarty. "The Stay-at-Home Labor Market: Google Searches, Unemployment Insurance, and Public Health Orders.” Fed Letter forthcoming, 2020.

[2] Nicolas Ajzenman, Tiago Cavalcanti, and Daniel Da Mata. "More than Words: Leaders Speech and Risky Behavior During a Pandemic.” Working Paper 2020.

[3] Hunt Allcott, Levi Boxell, Jacob C. Conway, Matthew Gentzkow, Michael Thaler, David Y. Yang. "Polarization and Public Health: Partisan Differences in Social Distancing during the Coronavirus Pandemic.” Journal of Public Economics Vol. 191, 2020.

[4] Asger Lau Andersen, Emil Toft Hansen, Niels Johannesen, and Adam Sheridan. "Consumer responses to the COVID-19 crisis: Evidence from bank account transaction data." Working Paper 2020.

[5] Natalie Bachas, Peter Ganong, Pascal J. Noel, Joseph S. Vavra, Arlene Wong, Diana Farrell, Fiona E. Greig. "Initial Impacts of the Pandemic on Consumer Behavior: Evidence from Linked Income, Spending, and Savings Data.” NBER Working Paper No. 27617, 2020.

[6] ChaeWon Baek, Peter B. McCrory, Todd Messer, and Preston Mui. "Unemployment effects of stay-athome orders: Evidence from high frequency claims data.” Review of Economics and Statistics, 2020.

[7] Scott R. Baker, R.A. Farrokhnia, Steffen Meyer, Michaela Pagel, Constantine Yannelis. "How Does Household Spending Respond to an Epidemic? Consumption During the 2020 COVID-19 Pandemic." The Review of Asset Pricing Studies Vol. 10, No. 4, 2020.

[8] John M. Barrios and Yael V. Hochberg. "Risk Perception Through the Lens of Politics in the Time of the COVID-19 Pandemic.” BFI Working Paper No. 2020-32, 2020.

[9] Alexander W. Bartik, Marianne Bertrand, Zoë B. Cullen, Edward L. Glaeser, Michael Luca, Christopher T. Stanton. "How Are Small Businesses Adjusting to COVID-19? Early Evidence from a Survey." NBER Working Paper No. 26989, 2020. 
[10] Abel Brodeur, Idaliya Grigoryeva, Lamis Kattan. "Stay-At-Home Orders, Social Distancing and Trust.” IZA Working Paper No. 13234, 2020.

[11] Adam Brzezinski, Guido Deiana, Valentin Kecht, and David Van Dijcke. "The COVID-19 Pandemic: Government vs. Community Action Across the United States." CEPR preprint in Covid Economics: Vetted and Real-Time Papers 2020.

[12] Brantly Callaway and Pedro HC SantAnna. "Difference-in-differences with multiple time periods." Journal of Econometrics 2020.

[13] Vasco M Carvalho, Stephen Hansen, Alvaro Ortiz, Juan Ramon Garcia, Tomasa Rodrigo, Sevi Rodriguez Mora, Jose Ruiz. "Tracking the Covid-19 Crisis With High-Resolution Transaction Data." CEPR Working Paper No. 14642, 2020.

[14] Joshua Coven and Arpit Gupta. "Disparities in Mobility Responses to COVID-19.” Working Paper 2020.

[15] Raj Chetty, John N. Friedman, Nathaniel Hendren, Michael Stepner, and the Opportunity Insights Team. "How Did COVID-19 and Stabilization Policies Affect Spending and Employment? A New Real-Time Economic Tracker Based on Private Sector Data.” Working Paper 2020.

[16] Olivier Coibion, Yuriy Gorodnichenko, and Michael Weber. "Labor markets during the COVID-19 crisis: A preliminary view.” NBER Working Paper 2020.

[17] Jonathan I. Dingel and Brent Neiman. "How Many Jobs Can be Done at Home?" Journal of Public Economics Vol. 189, 2020.

[18] Samuel Engle, John Stromme, and Anson Zhou. "Staying at Home: Mobility Effects of COVID-19." Working Paper 2020.

[19] Hanming Fang, Long Wang, and Yang Yang. "Human Mobility Restrictions and the Spread of the Novel Coronavirus (2019-nCoV) in China." Journal of Public Economics Vol. 191, 2020. 
[20] Austan Goolsbee, Chad Syverson. "Fear, Lockdown, and Diversion: Comparing Drivers of Pandemic Economic Decline 2021.” Journal of Public Economics Vol. 193, 2021.

[21] Sumedha Gupta, Thuy D. Nguyen, Felipe Lozano Rojas, Shyam Raman, Byungkyu Lee, Ana Bento, Kosali I. Simon, and Coady Wing. "Tracking Public and Private Response to the COVID-19 Epidemic: Evidence from State and Local Government Actions.” NBER Working Paper No. 27027, 2020.

[22] Stephen M. Kissler, Christine Tedijanto, Edward Goldstein, Yonatan H. Grad, and Marc Lipsitch. “Projecting the Transmission Dynamics of SARS-CoV-2 Through the Postpandemic Period.” Science Vol. 368, No. 6493, 2020.

[23] Daniel Lewis, Karel Mertens, James H. Stock. "U.S. Economic Activity During the Early Weeks of the SARS-Cov-2 Outbreak.” NBER Working Paper No. 26954, 2020.

[24] Simon Mongey, Laura Pilossoph, and Alex Weinberg. "Which Workers Bear the Burden of Social Distancing Policies?” BFI Working Paper No. 2020-51, 2020.

[25] Marcus Painter and Tian Qiu. "Political Beliefs affect Compliance with COVID-19 Social Distancing Orders" SSRN Working Paper 2020.

[26] Austin Wright, Konstantin Sonin, Jesse Driscoll, Jarnickae Wilson. "Poverty and Economic Dislocation Reduce Compliance with COVID-19 Shelter-in-Place Protocols." Journal of Economic Behavior \& Organization Vol. 180, 2020.

[27. NYTimes 2020a] Sarah Mervosh, Denise Lu and Vanessa Swales. "See Which States and Cities Have Told Residents to Stay at Home."

URL: https://www.nytimes.com/interactive/2020/us/coronavirus-stay-at-home-order.html Last updated: April 20th, 2020. New York Times. Accessed April 30th, 2020.

[28. NYTimes 2020b] Thomas Fuller, Jack Nicas and Kate Conger. "Can California Keep 9 Million People at Home?"

URL: https://www.nytimes.com/2020/03/17/us/california-shelter-in-place-coronavirus.html Last updated: March 17th, 2020. New York Times. Accessed April 30th, 2020. 
[29. NYTimes 2020c] Katie Rogers. "Trumps Scientists Push Back on His Claim That Virus May Not Return This Fall.”

URL: https://www.nytimes.com/2020/04/22/us/politics/trump-coronavirus-fall.html Last updated: April 22nd, 2020. New York Times. Accessed April 30th, 2020.

[30. NYTimes 2020d] Kenneth P. Vogel, Jim Rutenberg and Lisa Lerer. "The Quiet Hand of Conservative Groups in the Anti-Lockdown Protests."

URL: https://www.nytimes.com/2020/04/21/us/politics/coronavirus-protests-trump.html Last updated: April 21st, 2020. New York Times. Accessed April 30th, 2020.

[31. Unacast 2020] Unacast. "Unacast Social Distancing Dataset.”

URL: https://www.unacast.com/data-for-good Last updated: April 28th, 2020. New York Times. Accessed April 28th, 2020. 


\section{Figure 1: Stay-at-home order timing}

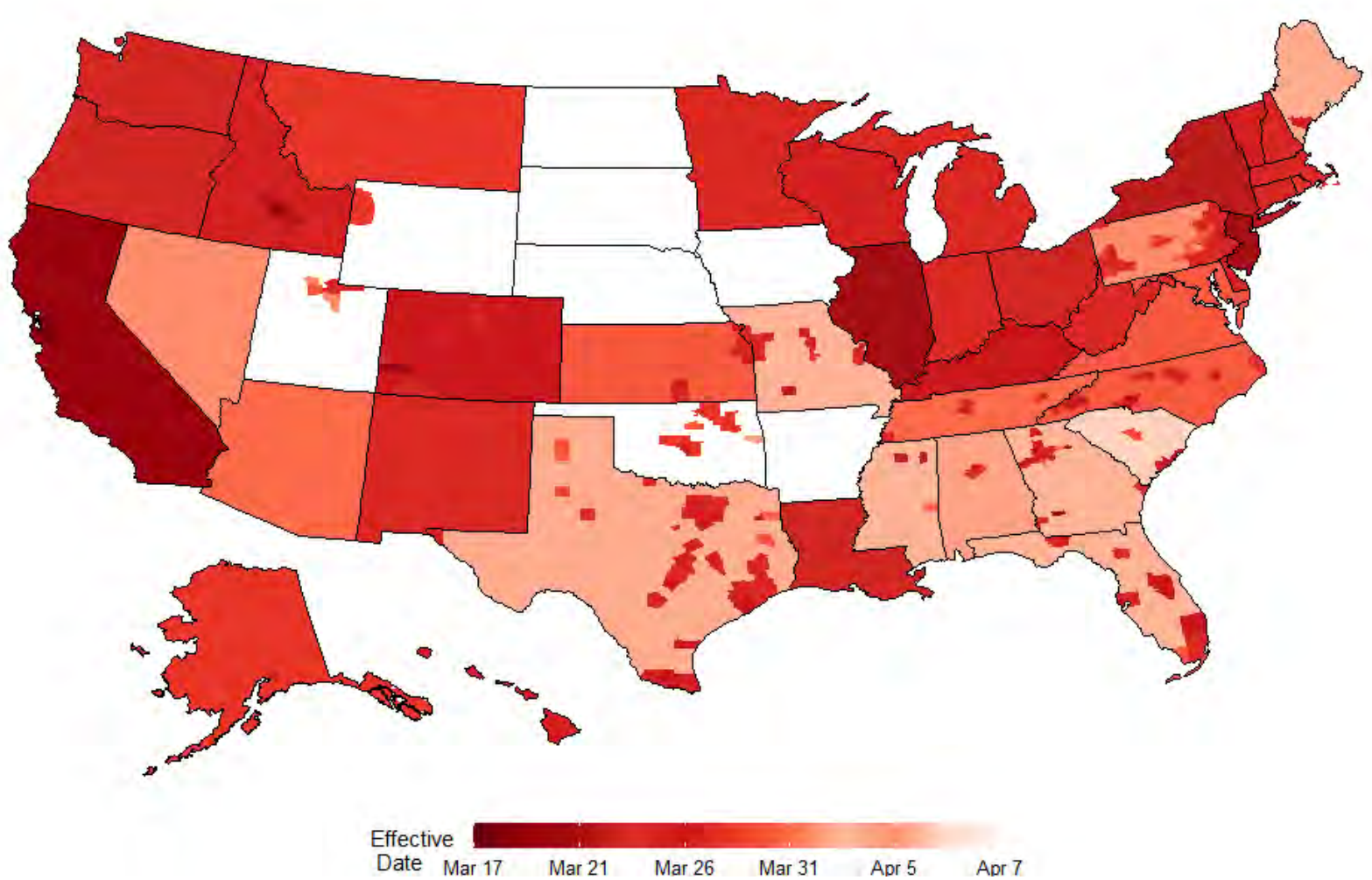

Notes: Last stay-at-home order is South Carolina on April 7th. A lighter color indicates a later stay-at-home order (e.g. Missouri, implemented on April 6th, 2020). Darker colors indicates states with earlier stay-at-home orders (e.g. California, implemented on March 19, 2020). The color gradient then varies depending on the timing of the stay-at-home order. 
Figure 2: Effect of stay-at-home orders on mobility and small-business revenue: event time

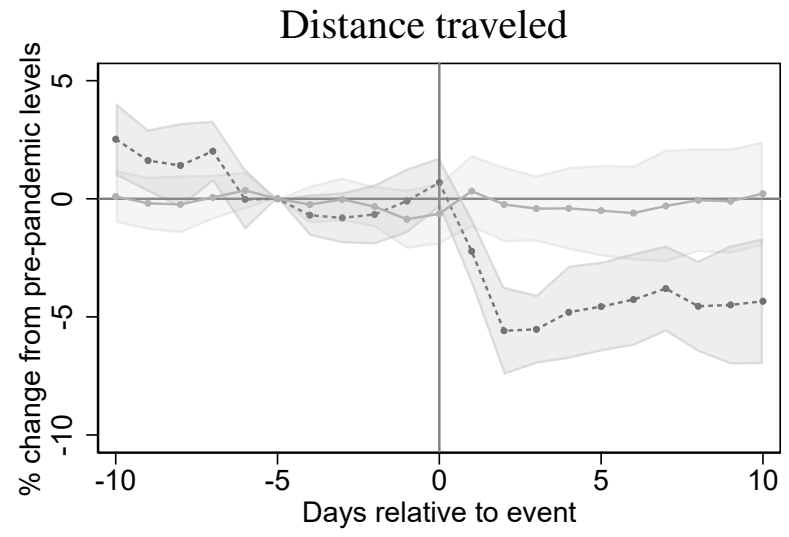

Event: 1st death

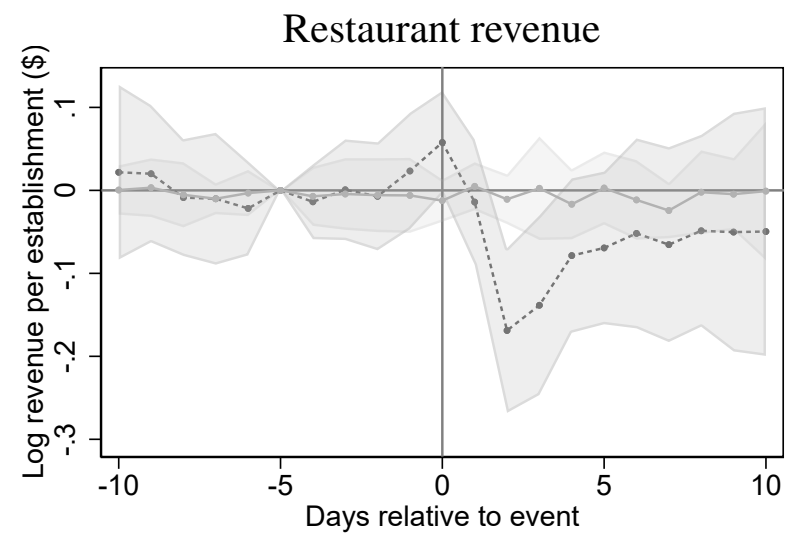

Event: stay-at-home

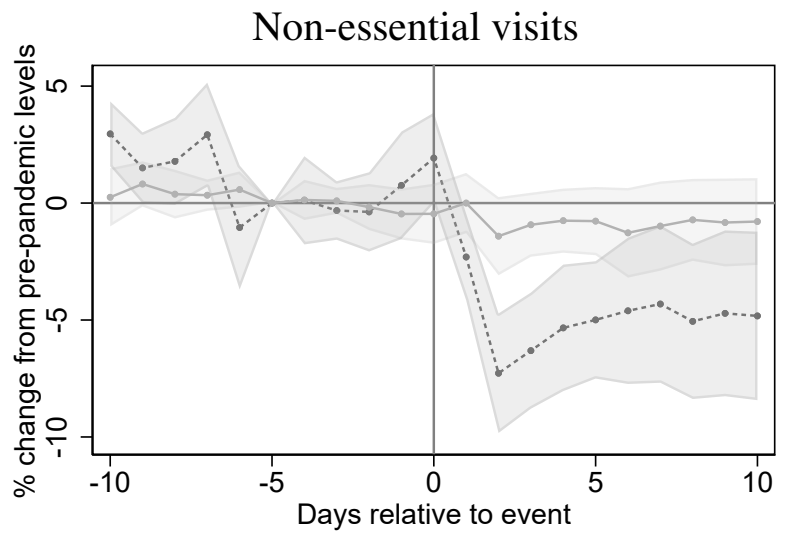

Event: stay-at-home —- Event: 1st death

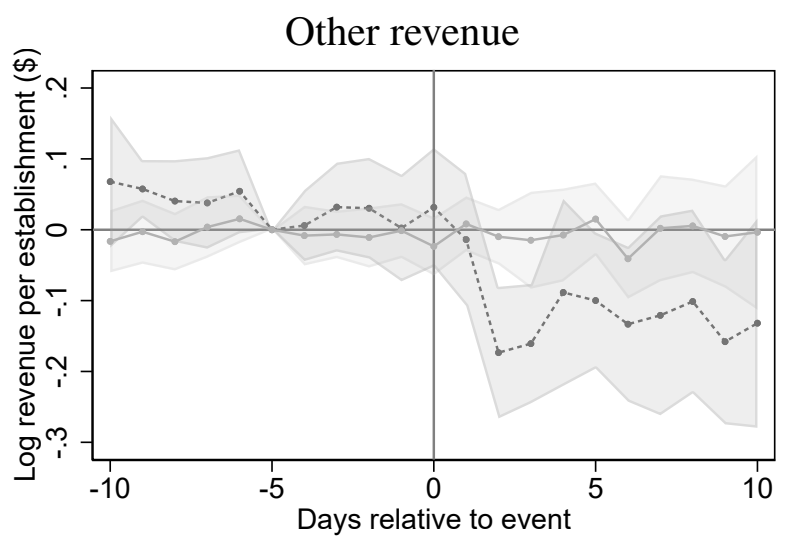

.. Event: stay-at-home Event: 1st death

Notes: Data at the county-day level. Plotted are coefficients on event time dummies from a regression which also includes date and county fixed effects and daily Covid-19 cases and deaths (in levels and logs) as controls. Regressions are weighted by county-level population in 2018, and 95\% confidence intervals. Standard errors are clustered two-way at the state and date level. Date 1 in event time is defined as the effective date of the stay-at-home order. Mobility outcomes derived from Unacast data. Per establishment revenue outcomes derived from Womply's panel of small businesses. 
Figure 3: Effect of stay-at-home orders on consumer spending at large businesses: event time

\section{(a) Data from Second Measure}
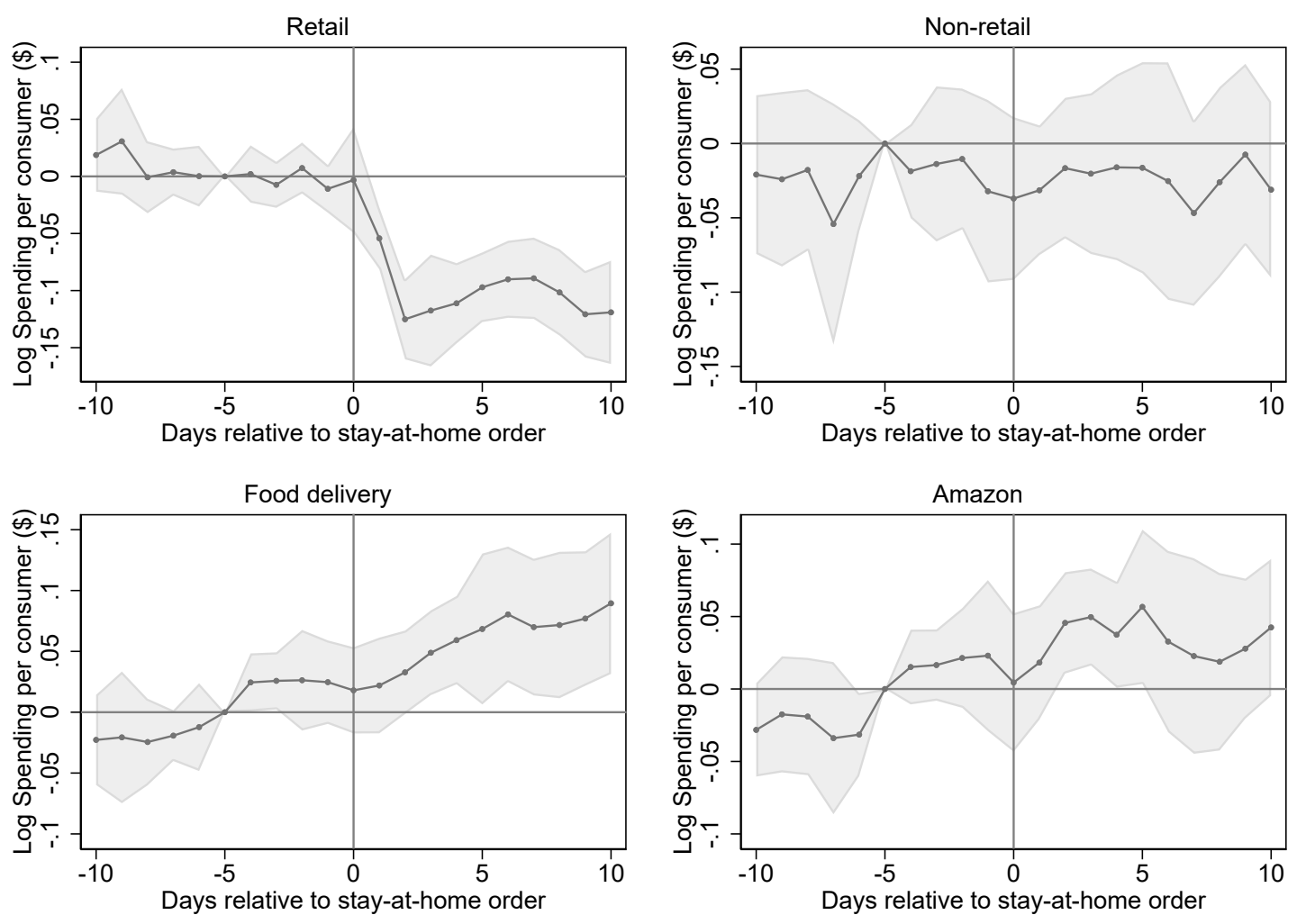

Notes: Data at the state-day level. Plotted are coefficients on event time dummies from a regression which also includes date and county fixed effects and daily Covid-19 cases and deaths as controls. Regressions are weighted by county-level population in 2018, and 95\% confidence intervals. Standard errors are clustered two-way at the state and date level. Date 1 in event time is defined as the date $>50 \%$ of the state population was covered by a stay-at-home order. Consumer spending data derived from Second Measure's panel of large firms. Spending is scaled by the average number of consumers in the panel in each state over the first week of March. 
Figure 4: Effect of stay-at-home orders: by county characteristics

By above and below median of household income

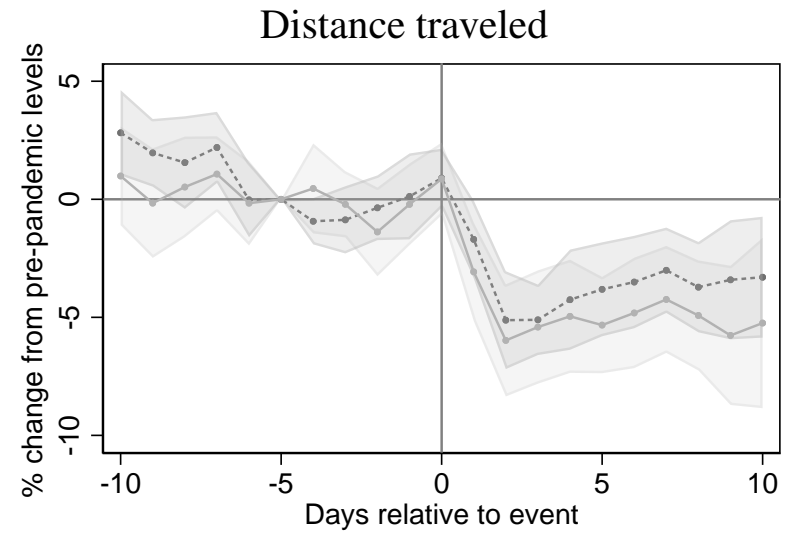

High income

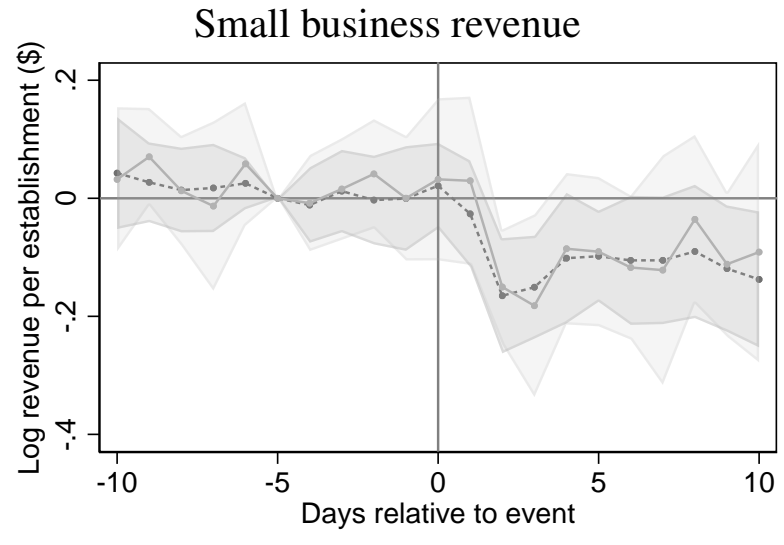

High income Low income

By 2016 presidential vote share

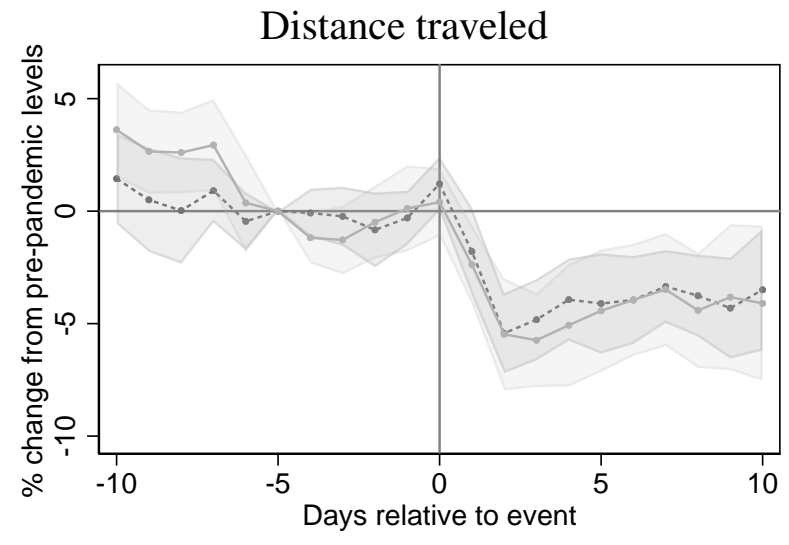

.......-.- Republican (2016) —— Democrat (2016)

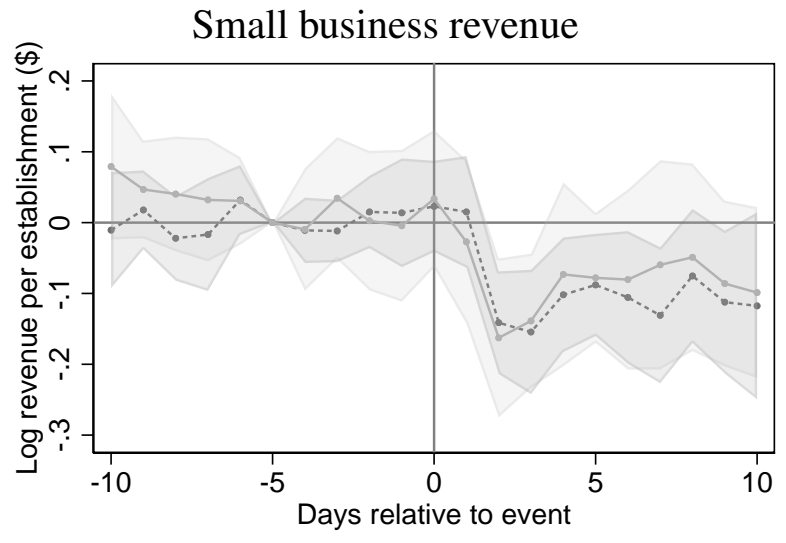

Republican (2016)

\section{By stay-at-home order timing}
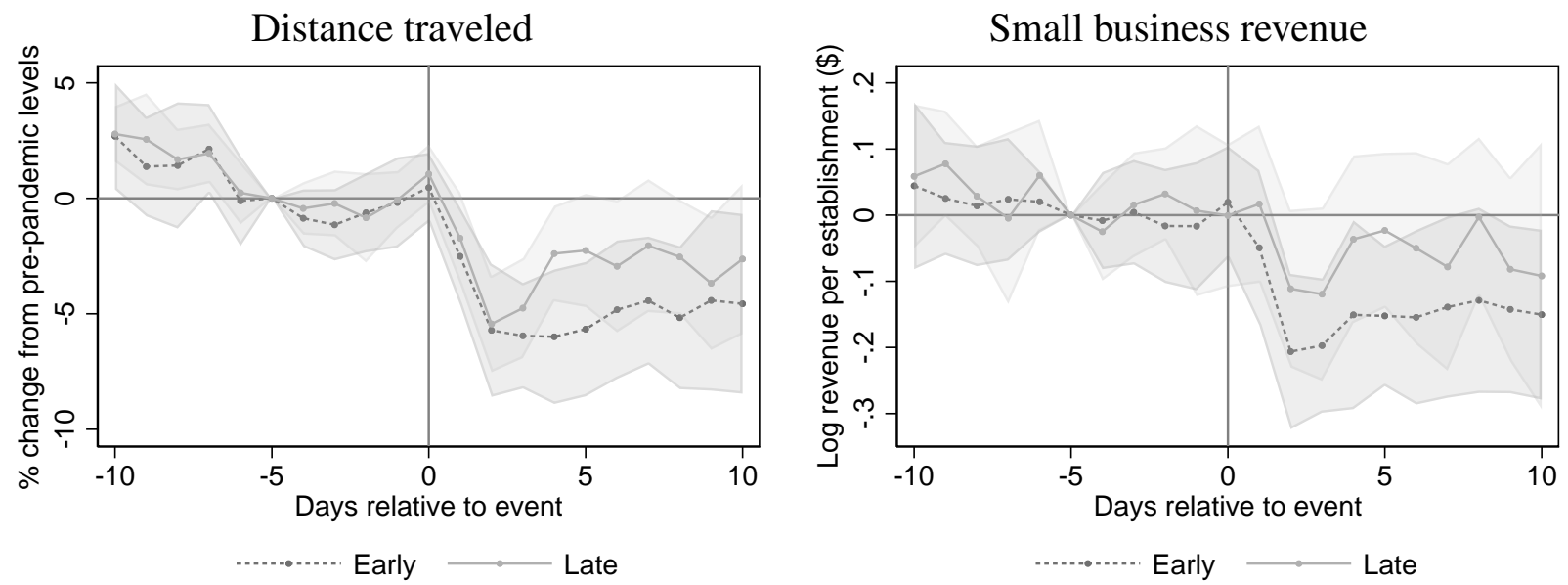

Notes: Data at the county-day level. Plotted are coefficients on event time dummies from a regression which also includes date and county fixed effects and daily Covid-19 cases and deaths (in levels and logs) as controls. Regressions are weighted by county-level population in 2018, and 95\% confidence intervals. Standard errors are clustered two-way at the state and date level. Date 1 in event time is defined as the effective date of the stay-at-home order. Mobility outcomes derived from Unacast data. Small business revenue outcomes derived from Womply's panel of small businesses. 
Table 1: Predictors of treatment effect: horse race of county-level characteristics

Predictors of change in distance traveled surrounding order ( $\mathrm{s}=0$ to $\mathrm{s}=2$ )

\begin{tabular}{lcccc}
\hline & $(1)$ & $(2)$ & $(3)$ & $(4)$ \\
\hline Above-median income & 0.79 & & & 0.57 \\
& $(0.79)$ & & & $(0.69)$ \\
Republican-supporting & & -0.43 & & -0.04 \\
& & $(0.72)$ & & $(0.63)$ \\
Rural & & & -1.31 & -1.06 \\
& & & $(1.05)$ & $(0.85)$ \\
Constant & $-8.61^{* * *}$ & $-6.68^{* * *}$ & $-5.77^{* * *}$ & $-7.03^{* * *}$ \\
& $(1.37)$ & $(1.14)$ & $(1.25)$ & $(1.33)$ \\
\hline Observations & 2,460 & 2,460 & 2,460 & 2,460 \\
$\mathrm{R}^{2}$ & 0.774 & 0.774 & 0.774 & 0.775 \\
Mean dep. var. & & & & \\
\hline
\end{tabular}

Predictors of change in small business spending surrounding order ( $s=0$ to $s=2$ )

\begin{tabular}{lcccc}
\hline & $(1)$ & $(2)$ & $(3)$ & $(4)$ \\
\hline Above-median income & 0.01 & & & 0.02 \\
& $(0.05)$ & & & $(0.05)$ \\
Republican-supporting & & 0.01 & & 0.01 \\
& & $(0.03)$ & & $(0.04)$ \\
Rural & & & 0.02 & 0.03 \\
& & & $(0.04)$ & $(0.03)$ \\
Constant & -0.10 & $-0.08^{* *}$ & $-0.10^{* *}$ & -0.15 \\
& $(0.10)$ & $(0.04)$ & $(0.04)$ & $(0.12)$ \\
\hline Observations & 2,482 & 2,482 & 2,482 & 2,482 \\
$\mathrm{R}^{2}$ & 0.804 & 0.804 & 0.804 & 0.804 \\
Mean dep. var. & & & & \\
\hline
\end{tabular}

Predictors of change in small business restaurant spending surrounding order ( $\mathrm{s}=0$ to $\mathrm{s}=2$ )

\begin{tabular}{lcccc}
\hline & $(1)$ & $(2)$ & $(3)$ & $(4)$ \\
\hline Above-median income & -0.05 & & & -0.03 \\
& $(0.04)$ & & & $(0.03)$ \\
Republican-supporting & & 0.06 & & 0.04 \\
& & $(0.04)$ & & $(0.04)$ \\
Rural & & & 0.09 & 0.06 \\
& & & $(0.06)$ & $(0.05)$ \\
Constant & -0.09 & $-0.24^{* * *}$ & $-0.27^{* * *}$ & $-0.24^{* * *}$ \\
& $(0.07)$ & $(0.05)$ & $(0.07)$ & $(0.08)$ \\
\hline Observations & 2,412 & 2,412 & 2,412 & 2,412 \\
$\mathrm{R}^{2}$ & 0.424 & 0.424 & 0.425 & 0.425 \\
Mean dep. var. & & & & \\
\hline
\end{tabular}

Notes: Data at the county-level. 2,642 counties implemented a stay-at-home order at some point through April 17th. Sample sizes are smaller because Unacast's mobility data and Womply's spending data are missing some observations for certain counties on certain days, especially in parts of March. Shown are regressions of changes in distance traveled on indicators for whether each county has above-median household income, supported a Republican in the 2016 presidential election, and was rural. Date fixed effects are included as controls in all models. In the last (fourth) model, we include all indicators. Standard errors are clustered by county. 


\section{Appendix: For Online Publication}

\section{Data Appendix}

We use three main data sources to measure consumer behavior in this paper: time series panels from Unacast, Womply, and Second Measure. In this appendix we describe the methodology underlying the construction of each of these datasets and their spatial coverage of the United States.

There are 3,142 counties and county-equivalent areas in the United States, which vary dramatically in size. The smallest county in our panel is Loving County, Texas, with a population of 152 people in 2018 according to the USDA's county-level summary files. For Loving County, our data sources report volatile numeric levels of revenue at small businesses (Womply), and we have no valid measure of visits to nonessential businesses in the Unacast data (the time series is unavailable or suppressed). On the other hand, in the largest county in our panel, Los Angeles County, CA (with a population of 10,105,518 in 2018 according to the USDA), we have valid and stable measures of spending at small businesses (Womply) and visits to non-essential businesses (Unacast). To ensure that our results are not affected by volatility in underlying spending and mobility measures in small counties, we population-weight all of the main results in our paper. Below, we report additional details about the coverage and representativeness of each of our sources.

\section{Unacast}

The Unacast data is constructed using a panel of around 25 million mobile phones. The percent change in mobility relative to pre-Covid-19 levels is calculated by comparing each day's level of mobility to the four same-weekday days before March 8th, 2020. ${ }^{27,28}$ Mobility changes are calculated as within-device (phone) changes in mobility on a given day versus the pre-Covid 19 period. These percent changes are then averaged across all devices in the county. In our analysis of Unacast's data, we use two of their mobility measures:

\footnotetext{
${ }^{27}$ For a complete methodological description, see: https://www. unacast.com/post/unacast-updates-social-distancing-scoreboard.

${ }^{28}$ For some additional details about the data, see: https://www.wsj.com/graphics/where-america-is-staying-home/
} 
average distance traveled and visits to non-essential businesses. ${ }^{29}$

Unacast does not report the exact size of their panel, but does report detailed information about the representativeness of their panel. ${ }^{30}$ To summarize the main conclusions of Unacast's internal study of representativeness, a comparison of the proportion of the population in each state to the proportion of Unacast's panel in each state shows a slight overcount of devices in Texas and Florida and a slight undercount of devices in California. Nevertheless, Unacast's geographic coverage largely mirrors the U.S. population. A neighborhood-level (Census block group) analysis shows that Unacast's panel covers high-income and low-income neighborhoods proportionally to those neighborhood's populations in the United States. Unacast also has representative coverage of neighborhoods with different average ages, with a slight overrepresentation of devices owned by people under the age of 20 .

\section{Womply}

Womply is a company that works with small businesses to provide business applications, APIs for online services, and marketing. They serve over 500,000 establishments across the United States. While Unacast's main business involves selling mobility data to firms, Womply's time series of small business spending is a byproduct of their main business. Womply collects data from their customers and then filters that data, removing inactive businesses and businesses with sales larger than the Small Business Association's size threshold that define which firms are small businesses. ${ }^{31,32}$ Womply relies on data describing credit and debit cards, so it does not include cash transactions in the aggregated totals. Womply updates the data on a daily basis, with a 5-day lag. The Womply panel of small businesses reports a total of 26 billion dollars of

\footnotetext{
${ }^{29}$ According to Unacast, "Non-essential businesses" include businesses specializing in Restaurants, Department Stores, Clothing Stores, Footwear, Discount Stores, Jewelry, Computers and Consumer Electronics, Gifts, Seasonal, Books, Office Supplies, Hair, Cosmetics and Beauty Supplies, Gyms and Fitness Facilities, Communications, New/Used Car Dealers, Hotels, Used Products, "Crafts, Toys, and Hobbies", Travel, "Spa, Massage, and Esthetics", Sports and Recreation, Weight Loss, Furnishings, Home and Housewares, Home Improvement and Building Supplies, "Printing, Copying, and Publishing", Theaters, Music, Amusement, Furnishing Rentals, Shared Offices and Coworking, Car Washes, Cannabis Retail, Flowers, Bars, Pubs, Cafes, Nightclubs, Cinemas, Casinos; Bowling Alleys, fitness Centers, Department Stores, MallS, Do-it-Yourself, Furniture, and Sports."

${ }^{30}$ https: / /www. unacast.com/resources/how-accurate-is-unacast-data

${ }^{31}$ See the spreadsheet at this link for the definition of those thresholds by industry: https://www.sba.gov/ document/support--table-size-standards.

${ }^{32}$ We classify as restaurants: restaurants, bars, lounges, beer and liquor stores, convenience stores, farmers markets, bakeries, candy and dessert stores, delis, food shops and markets, butchers, coffee shops, cafes and street vendors. We classify all other businesses as 'non-restaurant.'
} 
revenue in January, 2020. This represents $5.4 \%$ of total retail spending in January, $2020 .{ }^{33}$. On the average day in January, 2020, Womply’s panel covered \$271,300 of revenue from 103 small businesses per county in each of 3,089 counties with active data in our panel (equivalent to over 800 million dollars of revenue at over 300,000 merchants daily). ${ }^{34}$ The distribution of small businesses across counties is skewed, with the median county reporting 24 small businesses that earned a median of $\$ 27,697$ daily.

There is less public information from Womply about the temporal and spatial representativeness of their panel. However, Womply's counts of establishments are highly correlated $(\rho=0.98)$ with county-level population.

\section{Second Measure}

Unlike Womply and Unacast, Second Measure's panel of consumer spending is available at the state (not county) level. Second Measure attempts to carefully track spending at thousands of large firms in the United States. Their panel is derived from a sample of more than 4 million consumers' debit and credit card transactions.

Second Measure selects and attempts to re-weight their panel to match the U.S. population, but they do not publicly provide explicit measures of overall panel representativeness to researchers. However, Second Measure does analyze the relationship between consumer spending in their panel and reported sales for publicly traded companies that they track in their panel. Second Measure's panel closely tracks overall spending at several companies_-for example, Second Measure publicly reports closely tracking spending at Shake Shack, Ulta, and Amazon. ${ }^{35}$

\footnotetext{
${ }^{33}$ For total retail sales, see https://www. census.gov/retail/mrts/historic_releases.html These numbers are not directly comparable because Womply's data excludes cash purchases

${ }^{34}$ Small businesses are measured at the establishment level.

${ }^{35}$ For more details, see: https://assets.secondmeasure.com/SM_IntroDeck.pdf
} 


\section{Appendix Figures}

Figure A1: Stay-at-home orders and disease spread

Covid-19 cases (in thousands)

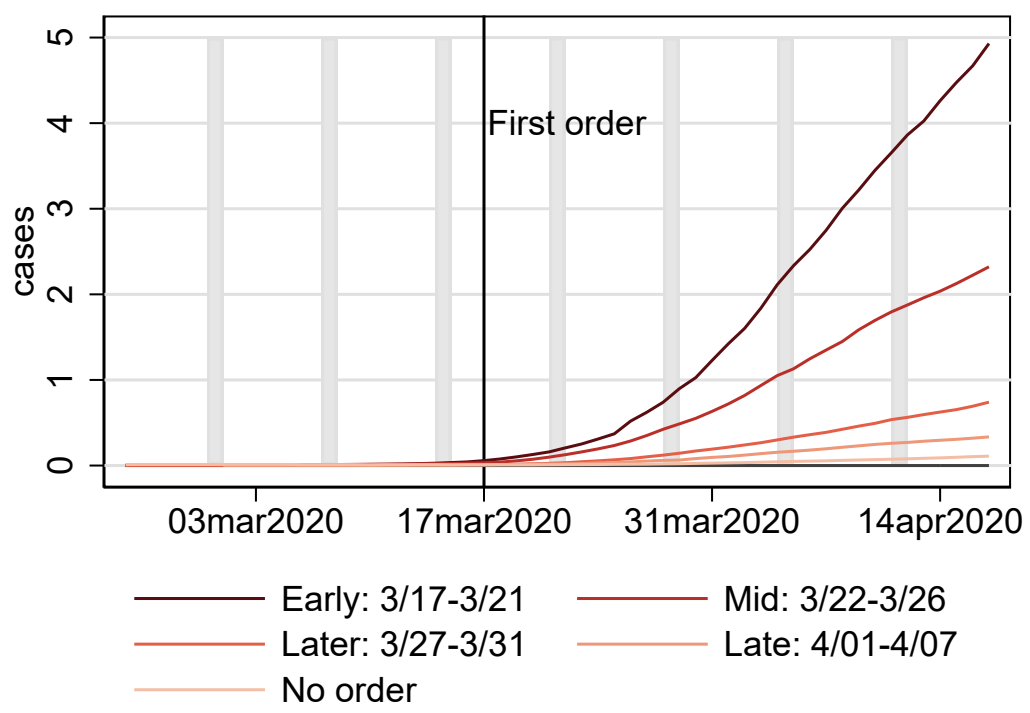

Covid-19 deaths

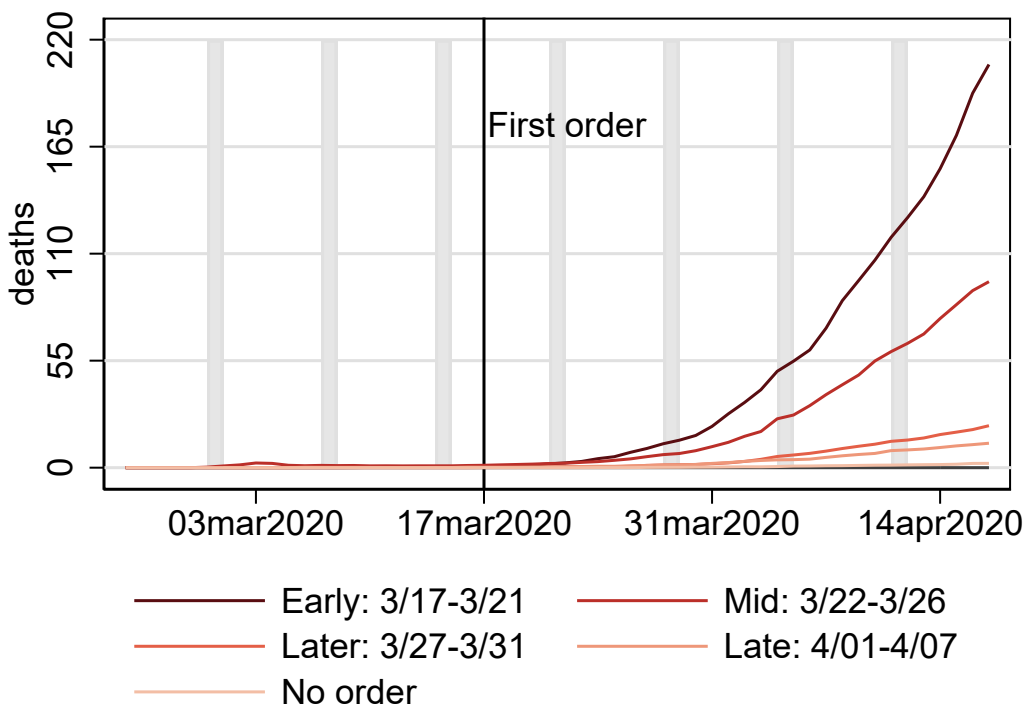

Notes: Shaded bars denote weekends. Vertical line marks the date of the first stay-at-home order (March 17th, 2020). Data drawn from the New York Times' publicly available Covid-19 case and death counts. Data are population-weighted county-level averages of cumulative case counts and death counts. 


\section{Figure A2: Aggregate trends}

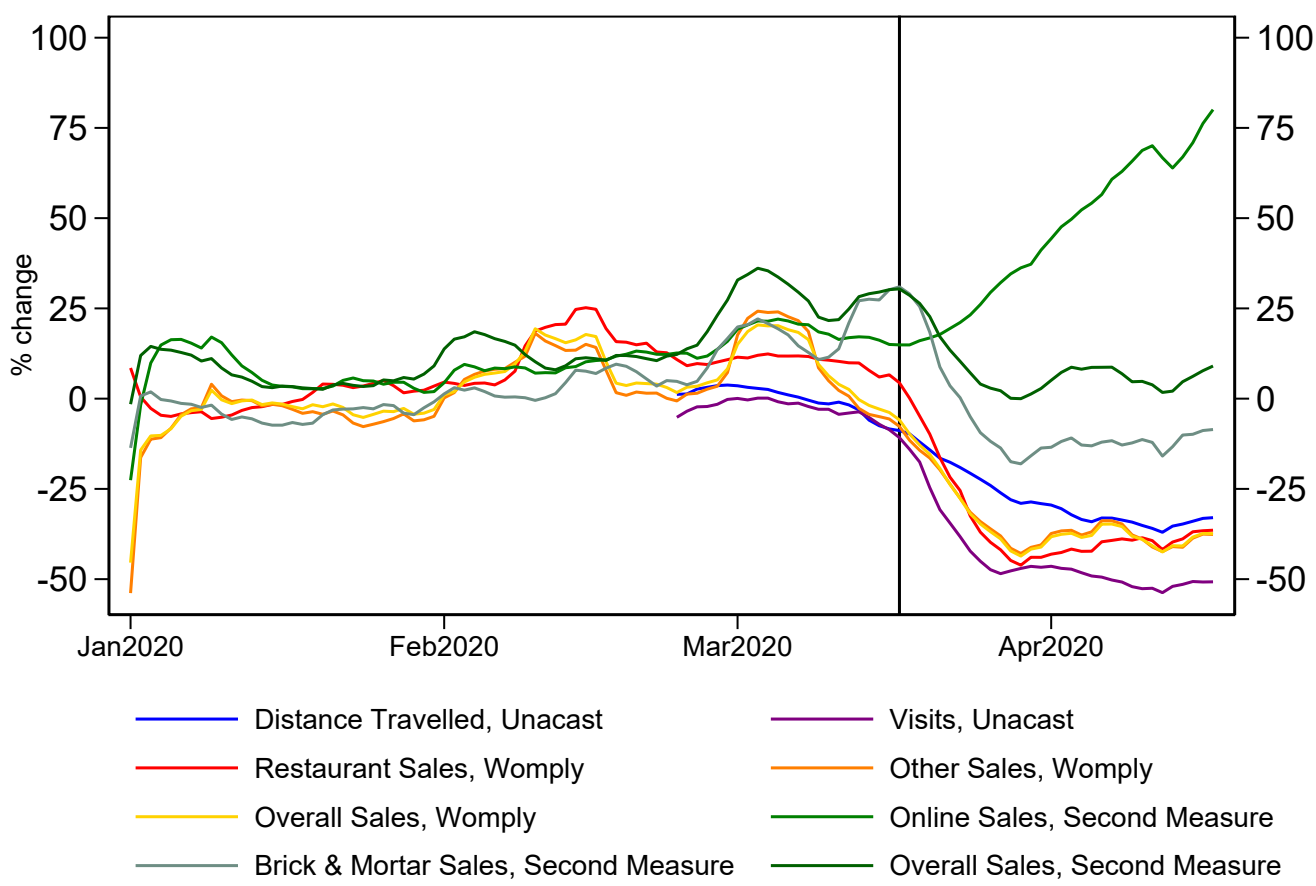

Note: Vertical line marks the date of the first stay-at-home order (March 17th, 2020).

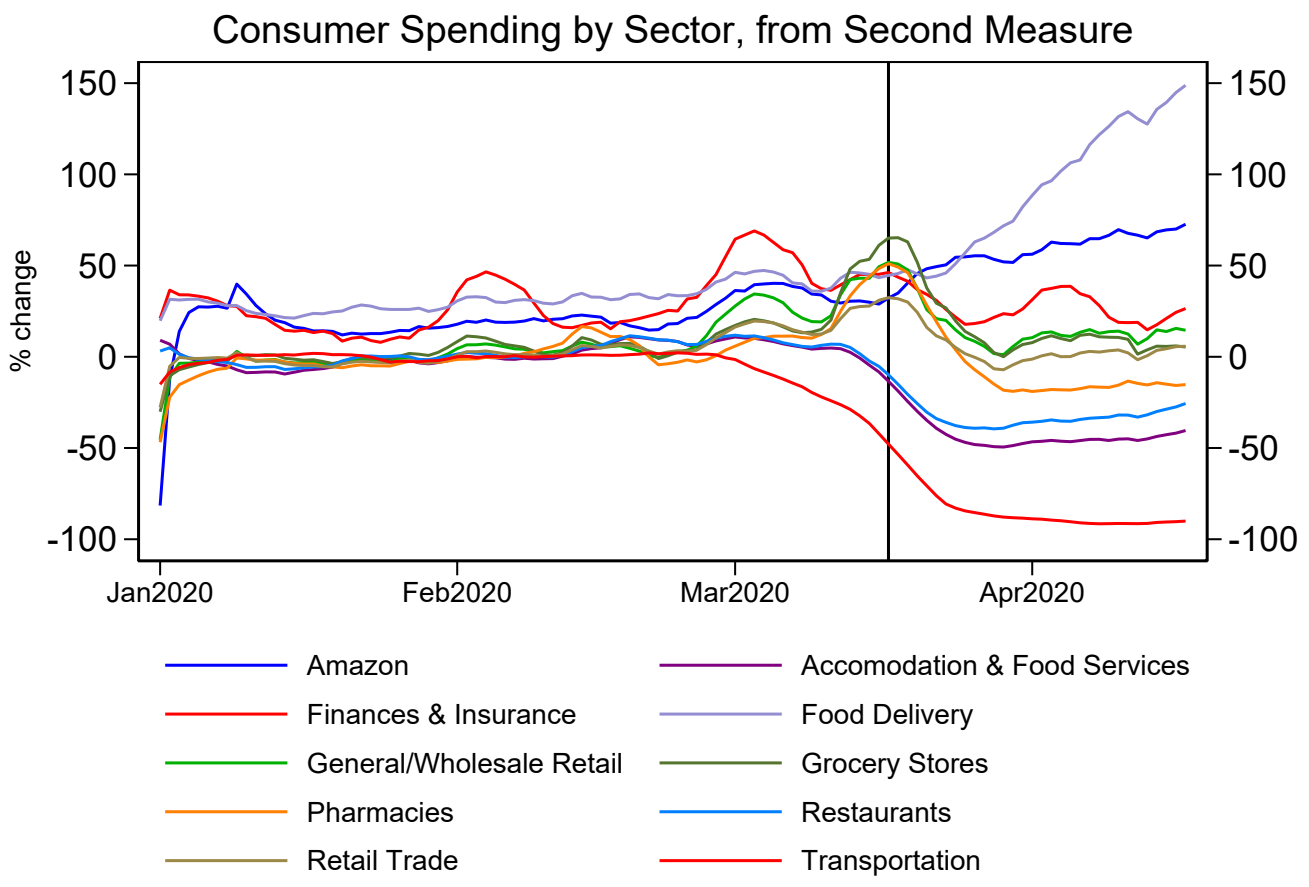

Note: Vertical line marks the date of the first stay-at-home order (March 17th, 2020).

Notes: Plotted values for sales are 7-day moving averages of percent changes in average daily sales from a year ago, same weekday. Values for distance traveled and visits (from Unacast) are 7-day moving averages of percent changes in mobility relative to the week since the national emergency was announced. Spikes in sales around the first of the month are due to online subscriptions and regular payments made on a monthly basis. 


\section{Figure A3: Effect of stay-at-home orders on mobility and small-business revenue}
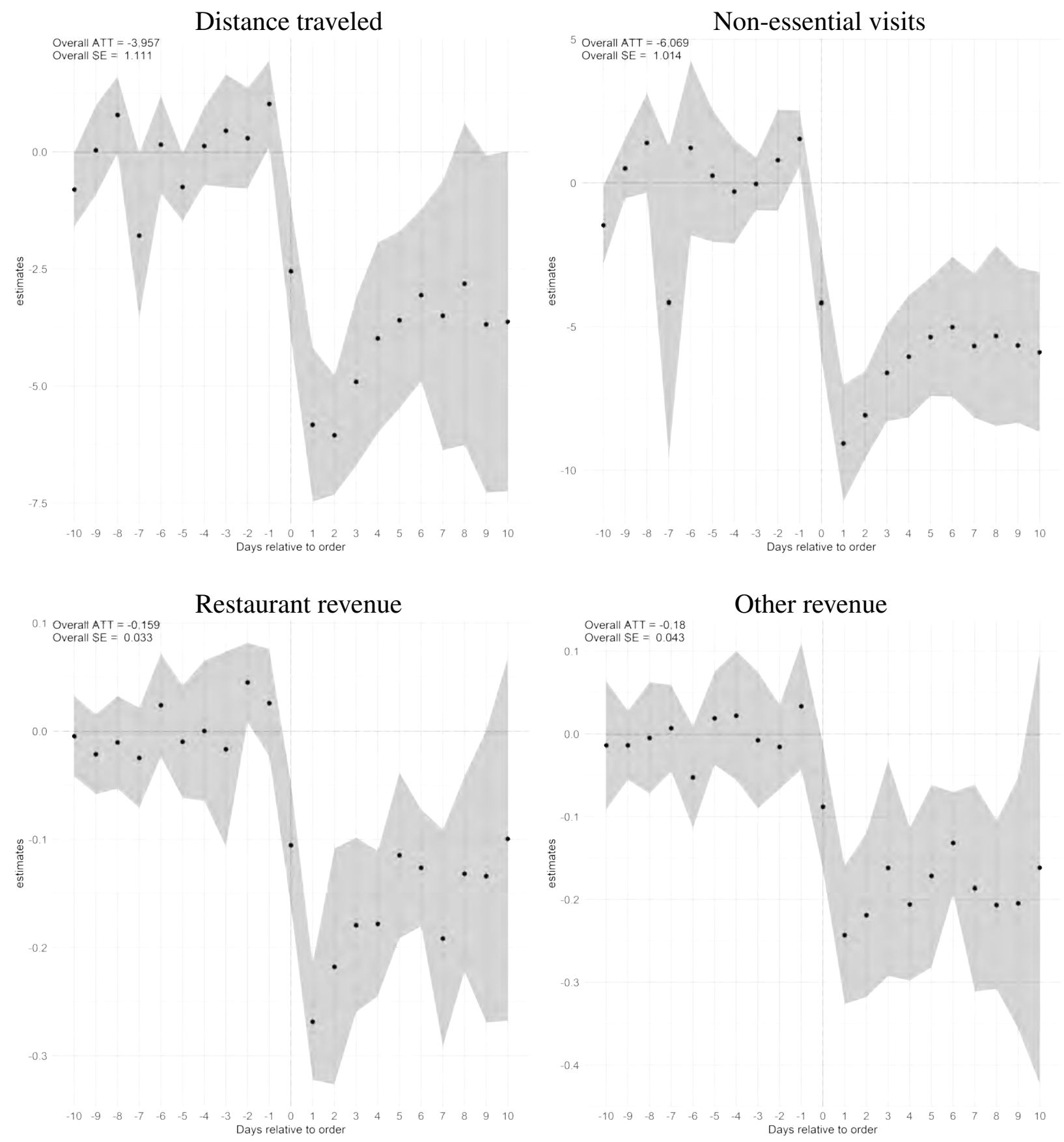

Notes: Data at the county-day level. Plotted are coefficients from the event-time estimates of Callaway and Sant'Anna (2020), weighted by countylevel population in 2018, and simultaneous 95\% confidence intervals. Standard errors are clustered by state. Date 0 in event time is defined as the effective date of the stay-at-home order. Mobility outcomes derived from Unacast data. Per establishment revenue outcomes derived from Womply's panel of small businesses. 
Figure A4: Effect of stay-at-home orders on consumer spending at large businesses: event time

Data from Second Measure
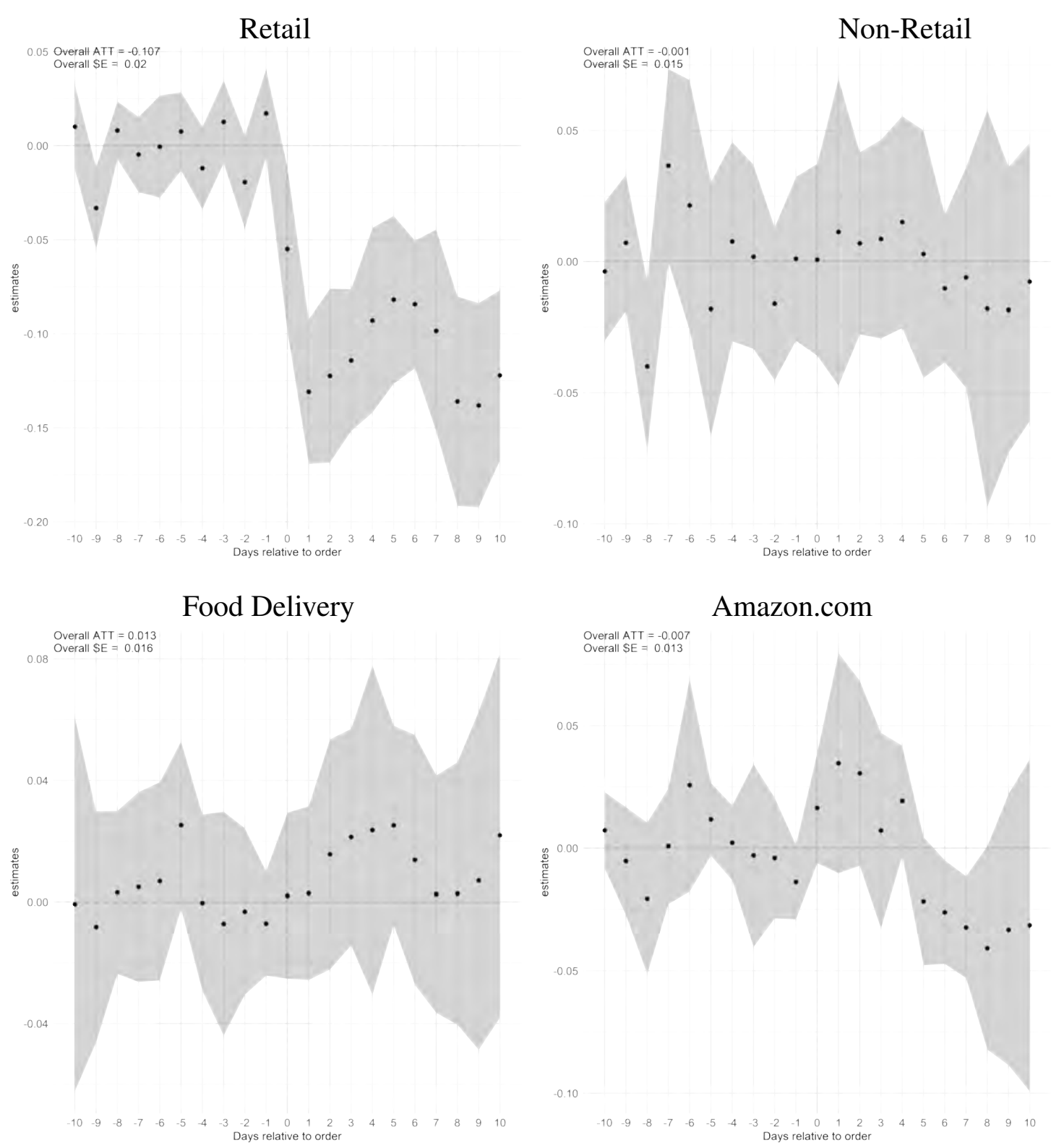

Notes: Data at the state-day level. Plotted are coefficients from the event-time estimates of Callaway and Sant'Anna (2020), weighted by countylevel population in 2018, and simultaneous $95 \%$ confidence intervals. Standard errors are clustered by state. Date 0 in event time is defined as the date $>50 \%$ of the state population was covered by a stay-at-home order. Consumer spending data derived from Second Measure's panel of large firms. Spending is scaled by the average number of consumers in the panel in each state over the first week of March. 
Figure A5: Histograms of stay-at-home effective dates

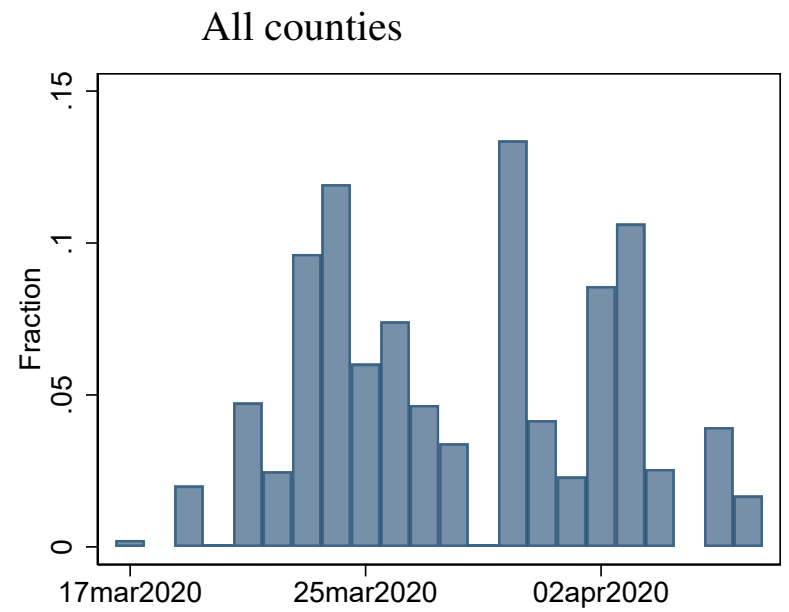

High versus low income

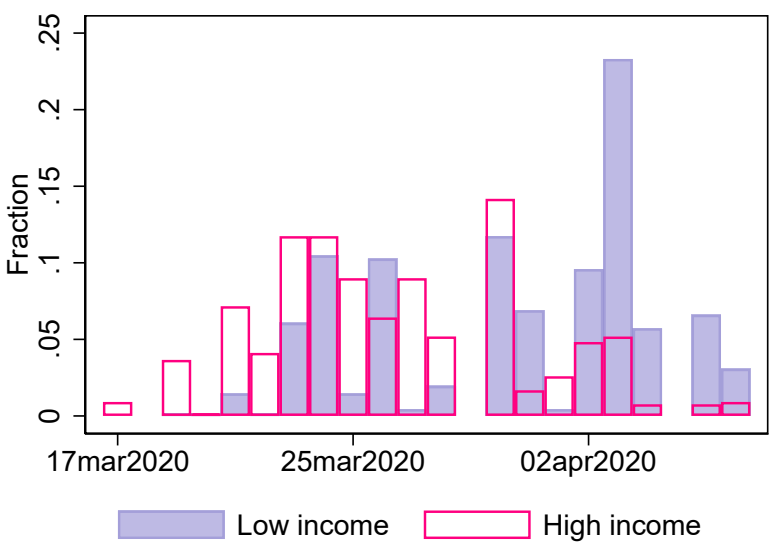

By 2016 vote share

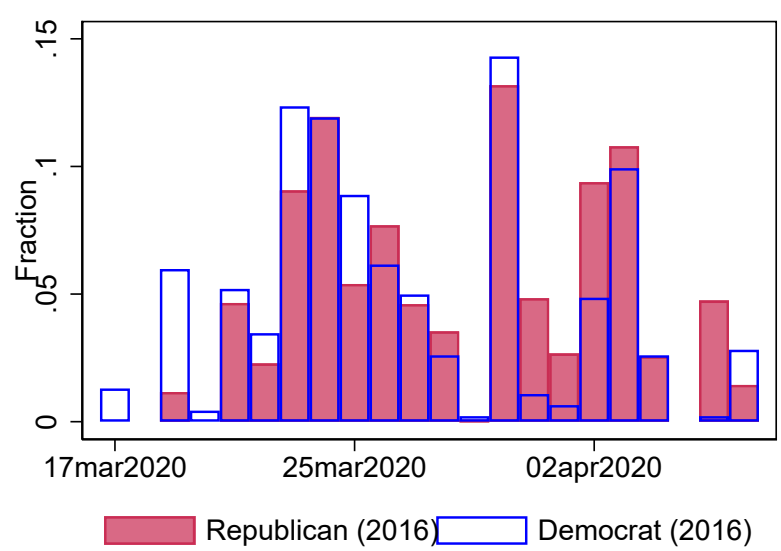

Early versus late orders

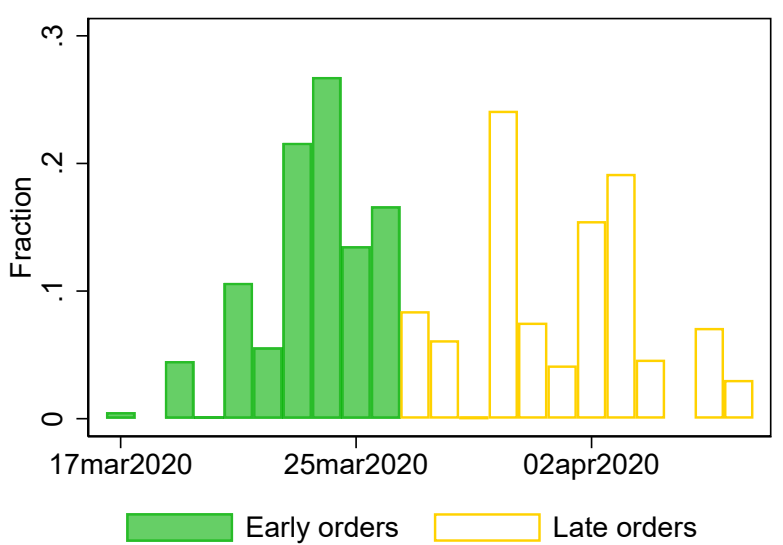

Notes: Stay-at-home orders drawn from our hand-collected county-level dataset. Histograms shows the distribution of stay-at-home orders across counties. Low-income and high-income counties are defined using the bottom-25\% and top-25\% of the median household income distribution. Republican and Democrat-supporting counties are defined using 2016 vote share, splitting counties by whether they supported or opposed a Republican in the 2016 presidential election. 
Figure A6: Effect of stay-at-home orders on mobility and revenue: calendar time

Distance traveled
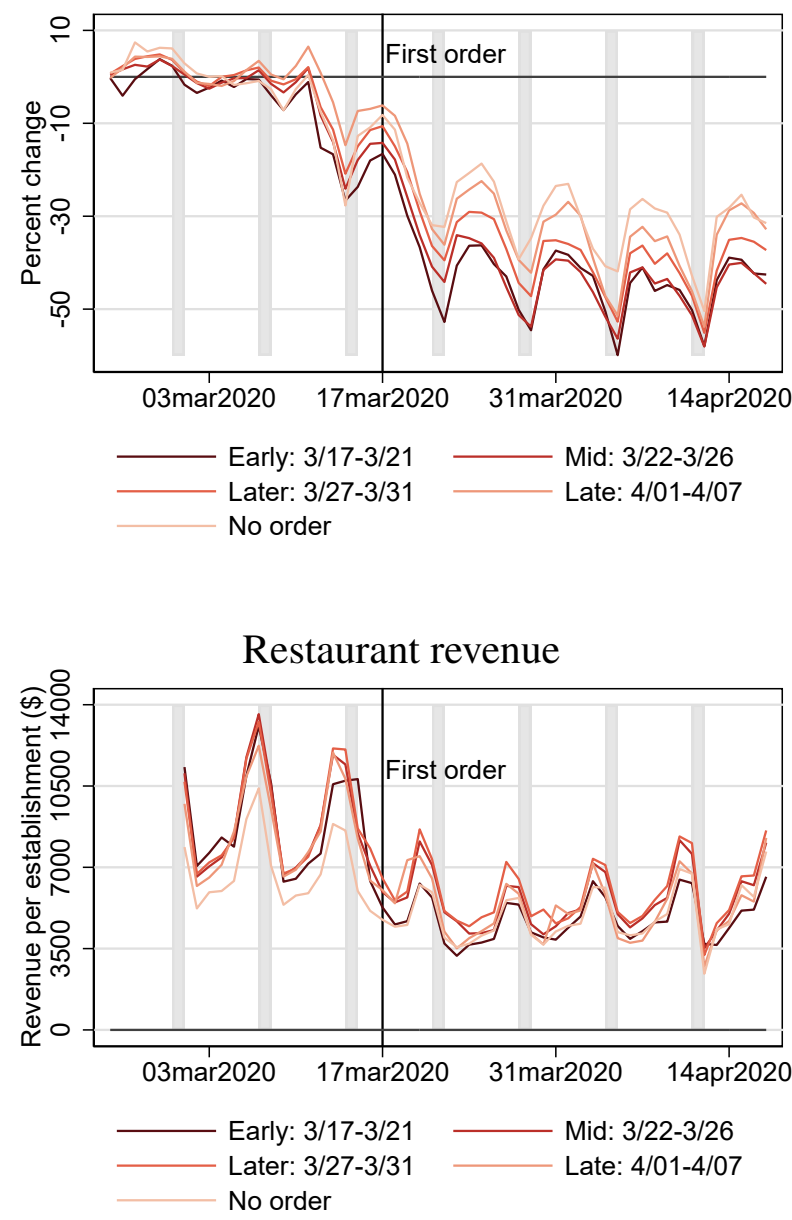

Non-essential visits
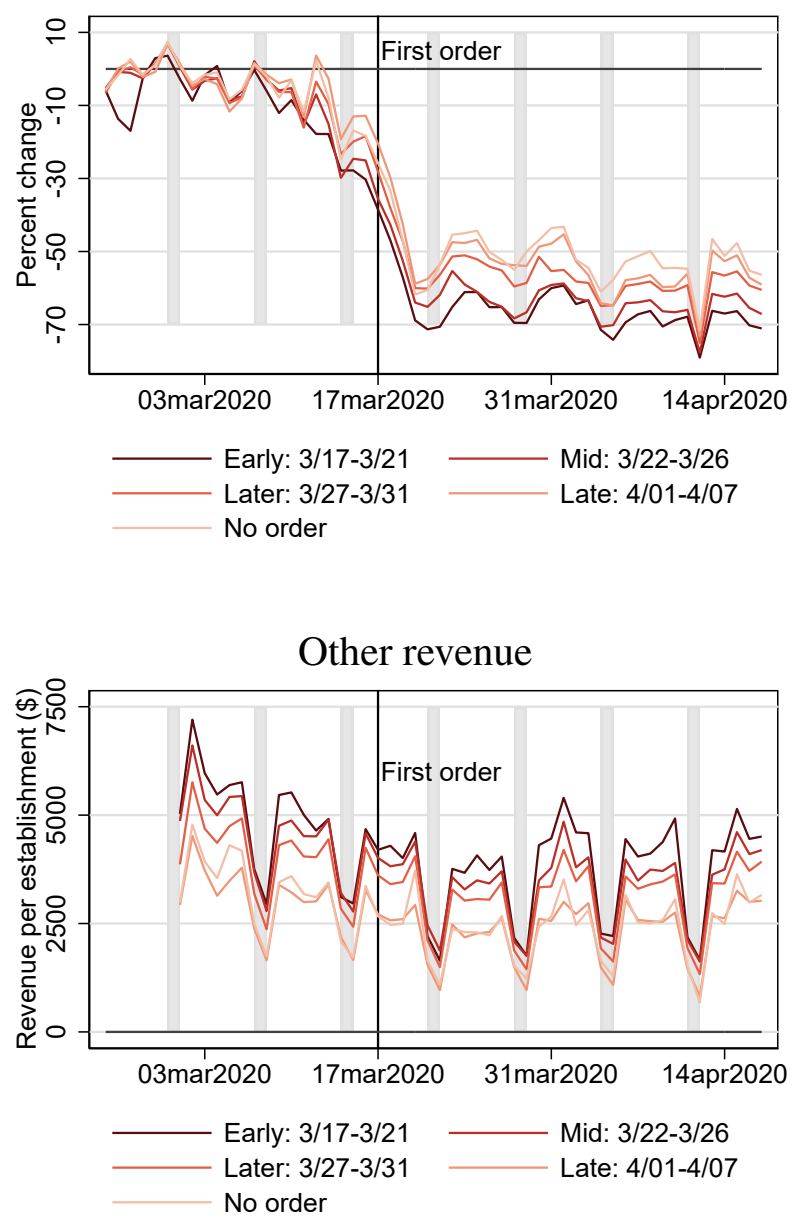

Notes: Shaded bars denote weekends. Vertical lines marks the date of the first stay-at-home order (March 17th, 2020). Mobility outcomes derived from Unacast data. Per establishment revenue outcomes derived from Womply's panel of small businesses. Data are population-weighted countylevel averages of per establishment revenue by category. 
Figure A7: Variation in geographic coverage of stay-at-home orders

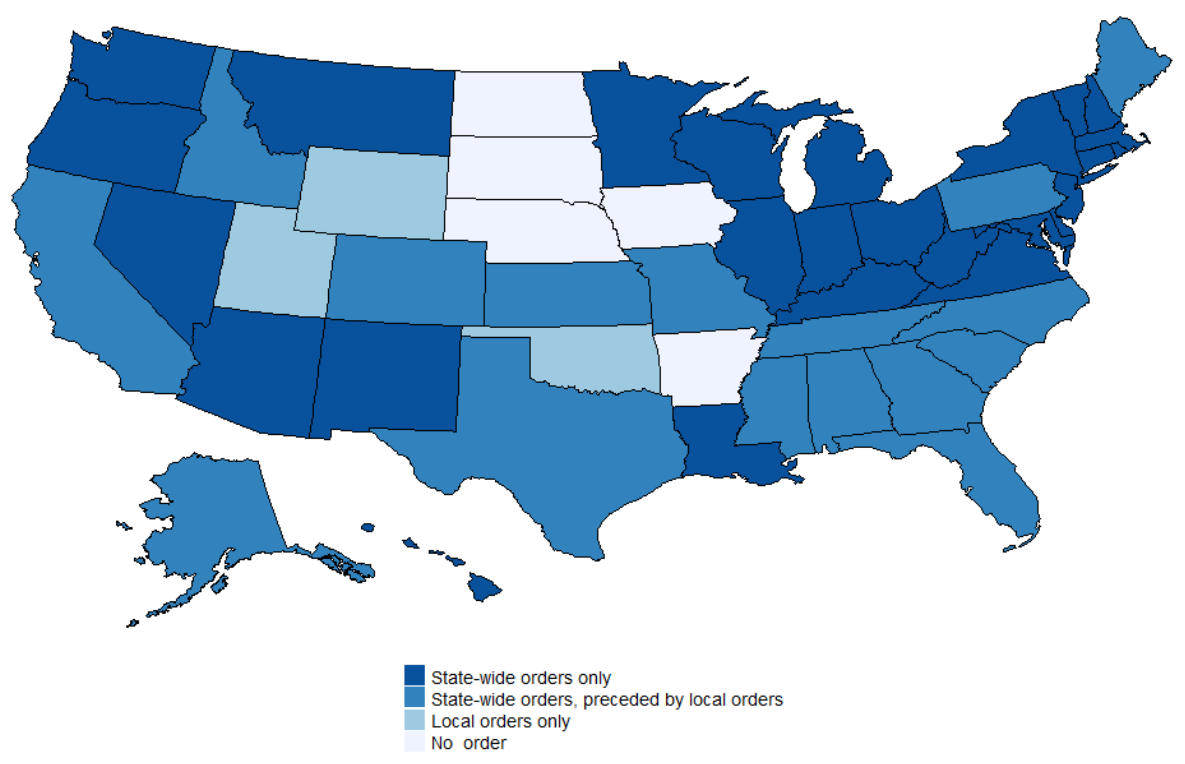

Notes: Data shown through April 7th. 
Figure A8: Effect of stay-at-home orders on consumer spending at large businesses: event time

\section{Data from Second Measure}
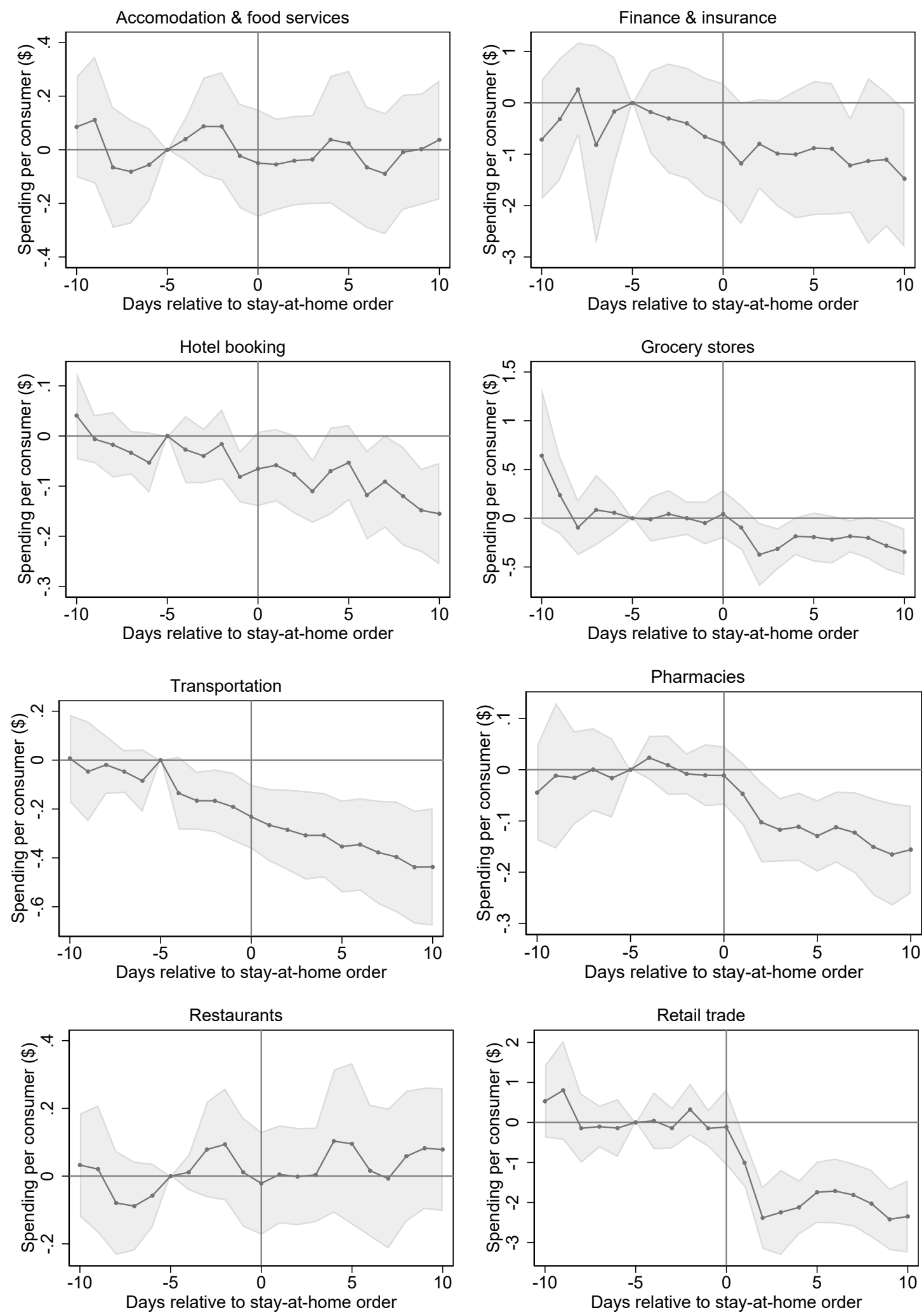

Notes: Data at the state-day level. Plotted are coefficients on event time dummies from a regression which also includes date and state fixed effects as controls. Regressions are weighted by state-level population in 2018 , and $95 \%$ confidence intervals. Standard errors are clustered two-way at the state and date level. Date 1 in event time is defined as the date $>50 \%$ of the state population was covered by a stay-at-home order. Only states with at least 5 days of post-event data included (event time 0-4). Consumer spending data derived from Second Measure's panel of large firms. Spending is scaled by the average number of consumers in the panel in each state over the first week of March. The restaurants category combines NAICS codes 722511,722513 , and 722514 
Figure A9: Effect of stay-at-home orders: by county characteristics

By above and below median of household income

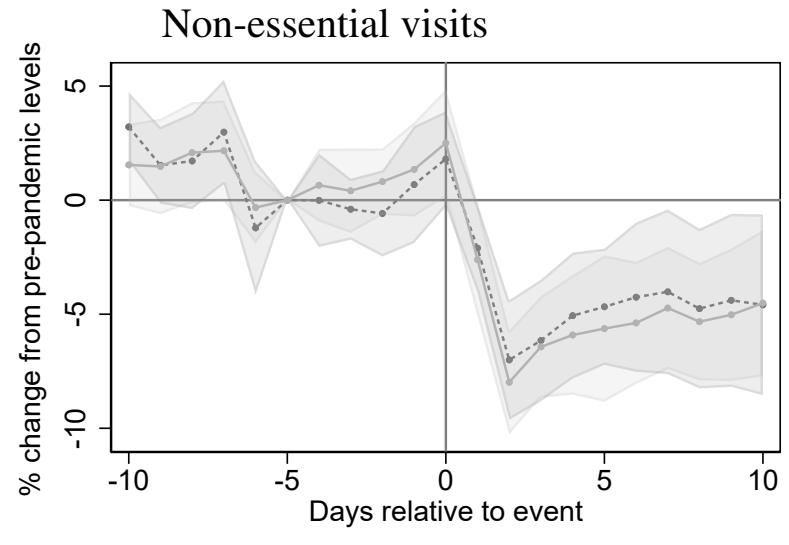

High income

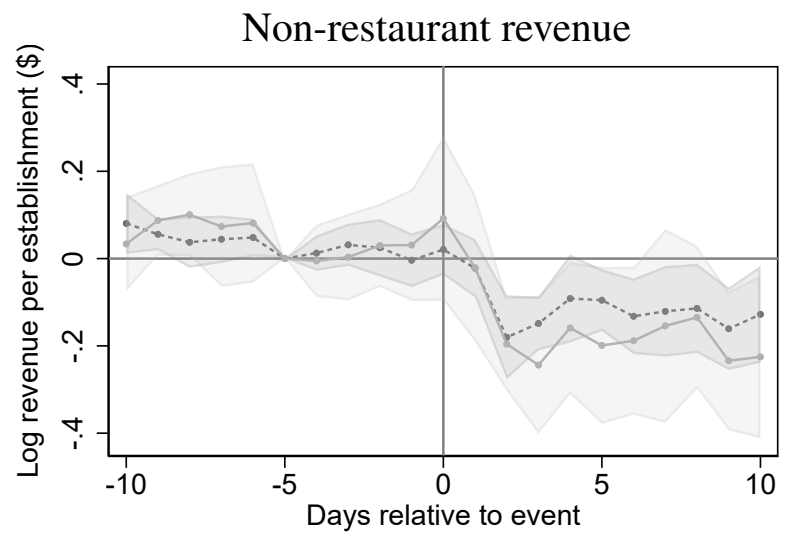

High income Low income

By 2016 presidential vote share

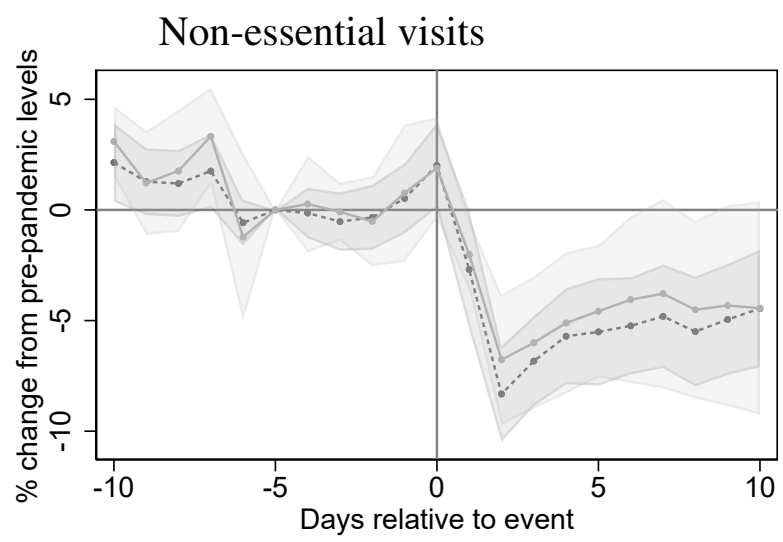

........- Republican (2016) —_ Democrat (2016)

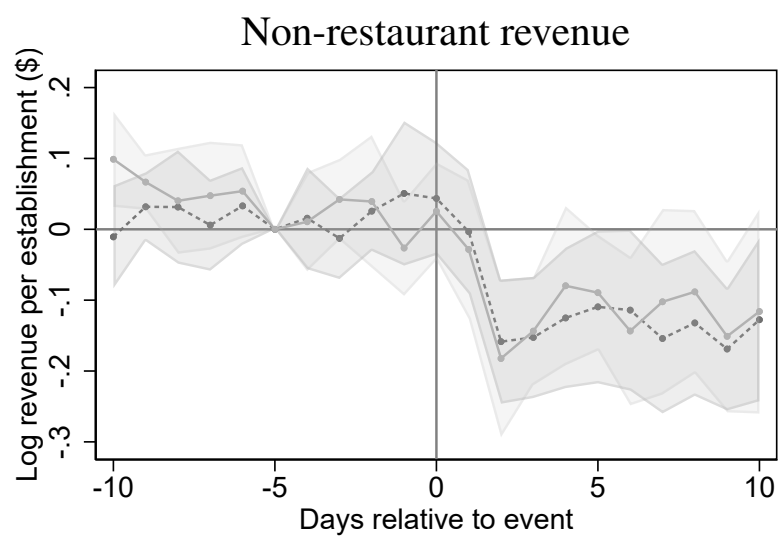

Republican (2016) Democrat (2016)

\section{By stay-at-home order timing}
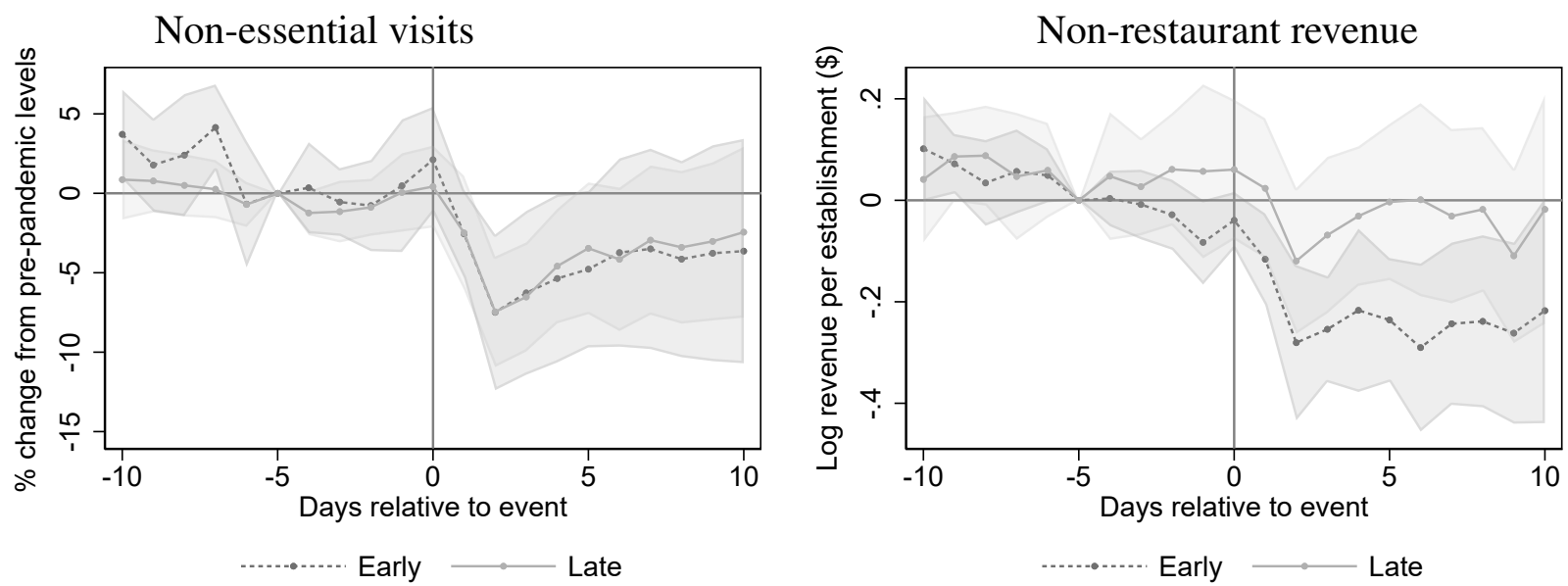

Notes: Data at the county-day level. Plotted are coefficients on event time dummies from a regression which also includes date and county fixed effects and daily Covid-19 cases and deaths (in levels and logs) as controls. Regressions are weighted by county-level population in 2018, and 95\% confidence intervals. Standard errors are clustered two-way at the state and date level. Date 1 in event time is defined as the effective date of the stay-at-home order. Mobility outcomes derived from Unacast data. Small business revenue outcomes derived from Womply's panel of small businesses. 
Figure A10: Unacast and Womply in event time: by timing and politics
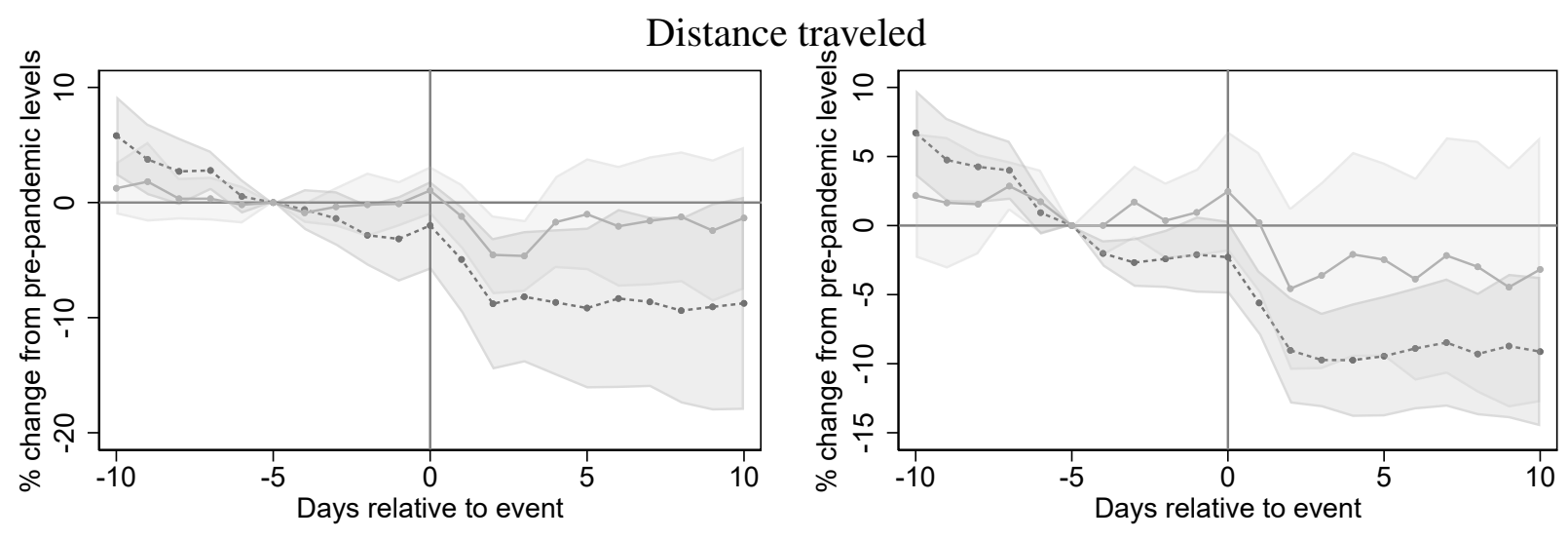

........ Republican: Early — Republican: Late
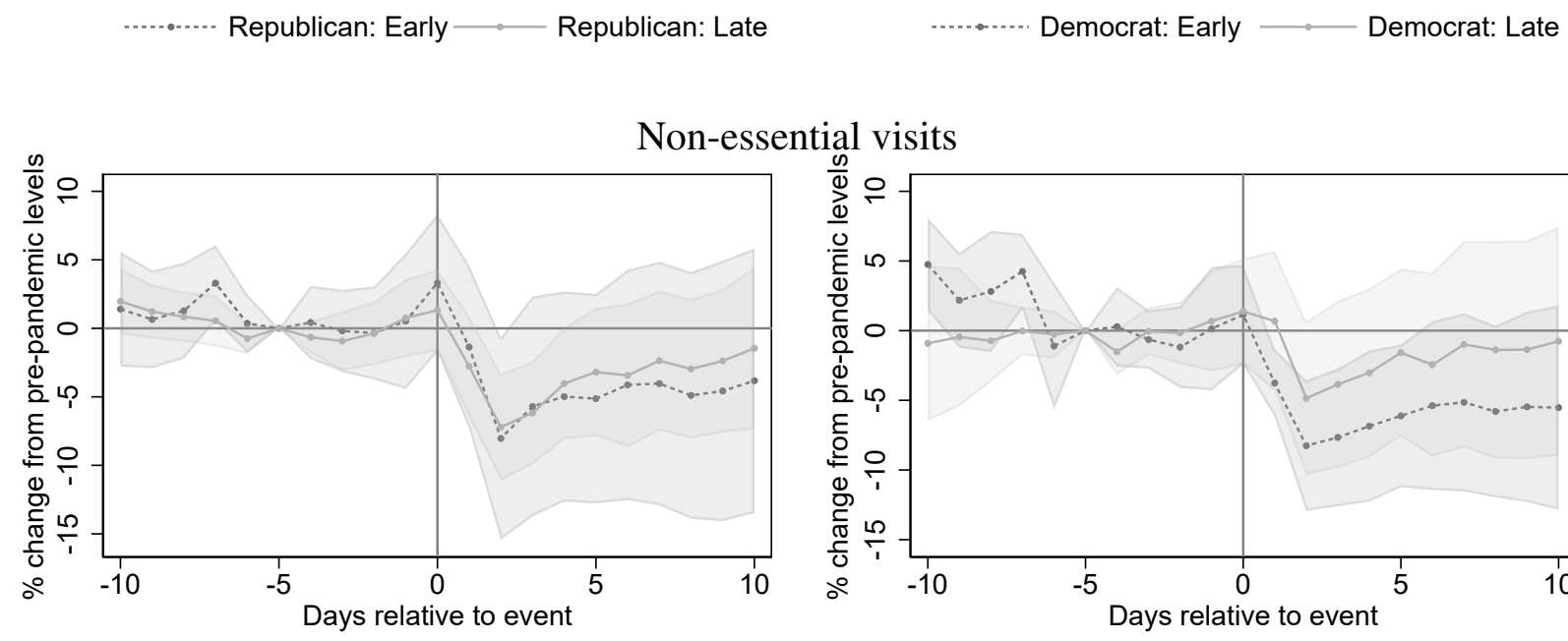

…-...- Republican: Early —— Republican: Late
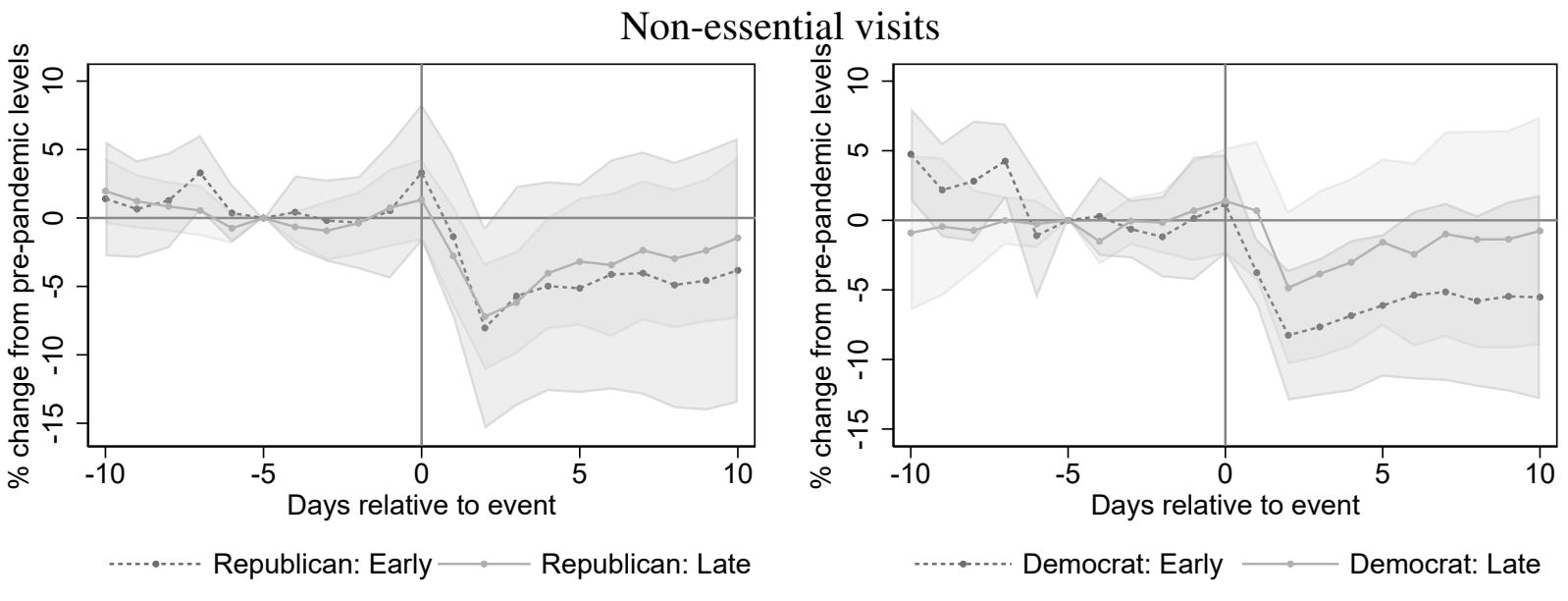

…..... Democrat: Early D Democrat: Late
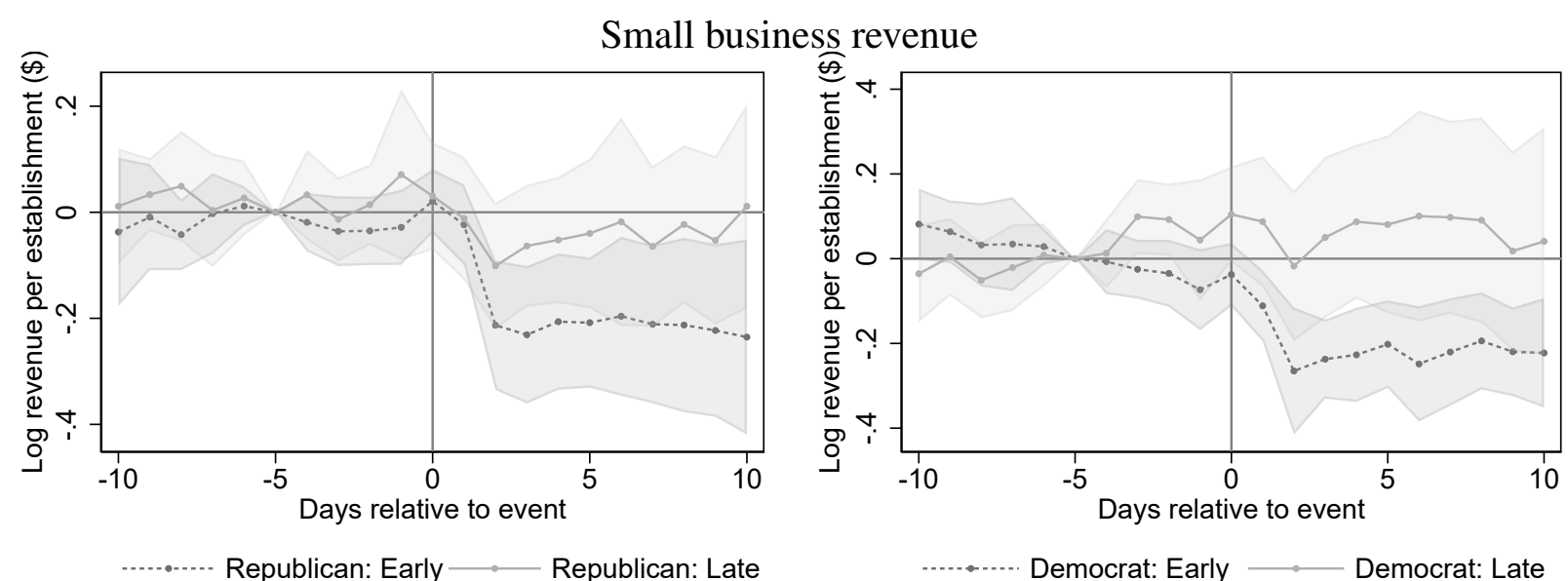

Notes: Data at the county-day level. Plotted are coefficients on event time dummies from a regression which also includes date and county fixed effects and daily Covid-19 cases and deaths (in levels and logs) as controls. Regressions are weighted by county-level population in 2018, and $95 \%$ confidence intervals. Standard errors are clustered two-way at the state and date level. Date 1 in event time is defined as the effective date of the stay-at-home order. Mobility outcomes derived from Unacast data. Per establishment revenue outcomes derived from Womply's panel of small businesses. 
Figure A11: Effect of stay-at-home orders on mobility and revenue: adding state-by-date fixed effects

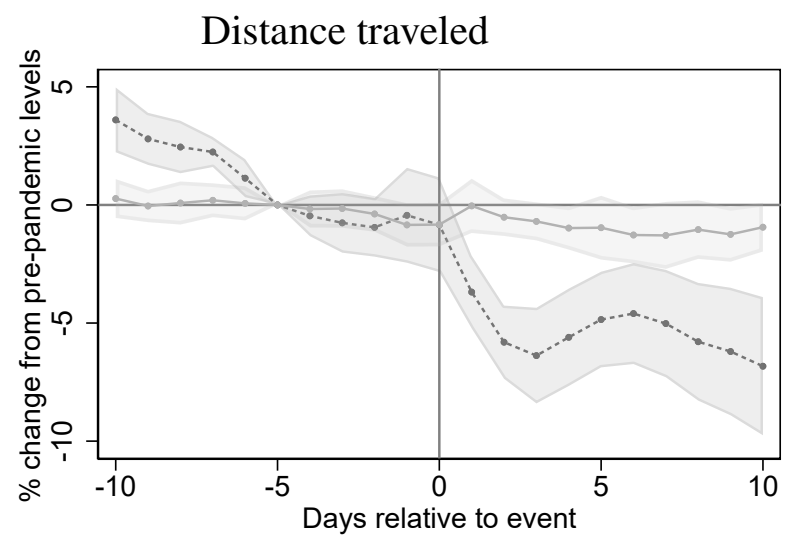

Event: 1st death

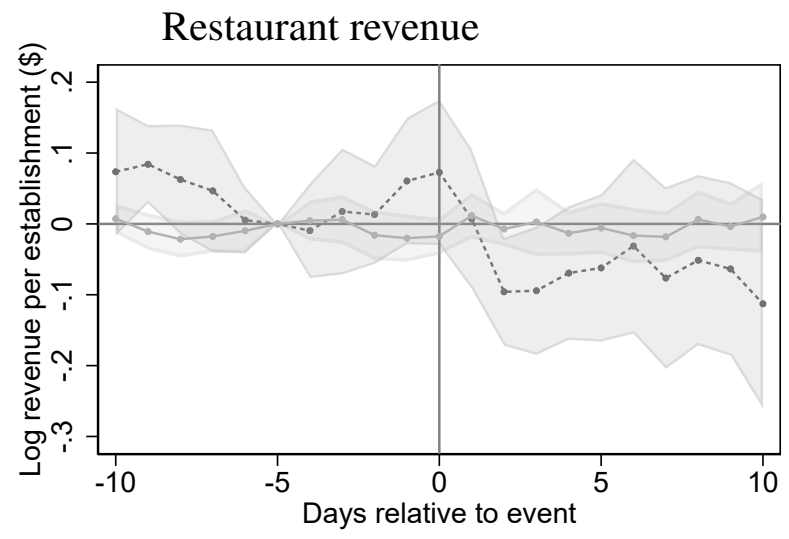

…-..... Event: stay-at-home —_ Event: 1st death

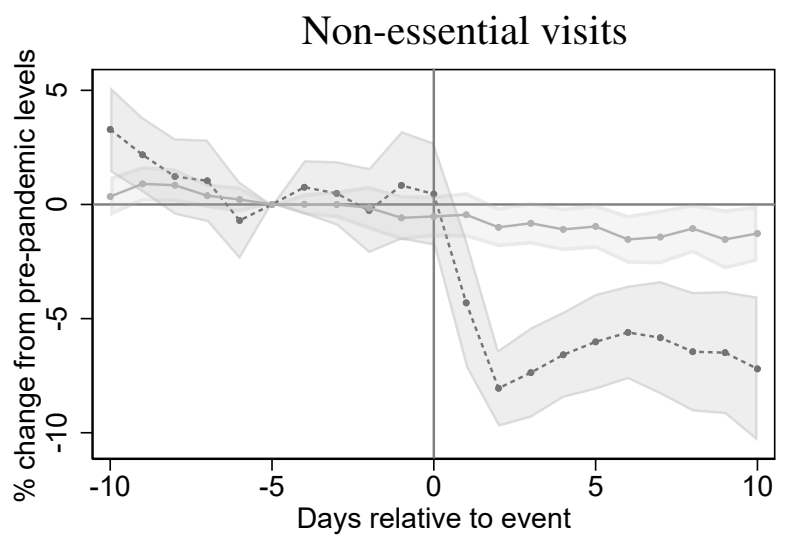

Event: 1st death

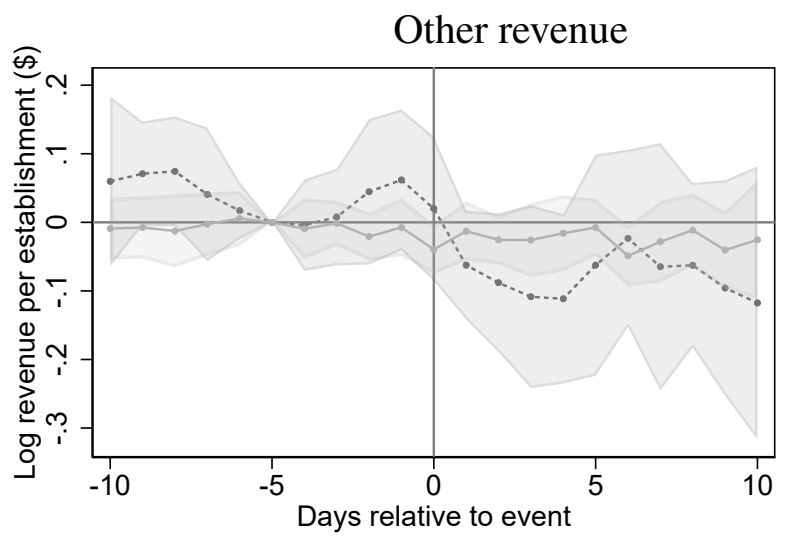

…...... Event: stay-at-home ——Event: 1st death

Notes: Data at the county-day level; only states with within state variation in the timing of stay-at-home orders are included. See Figure A7 for a map describing the source of variation once we control for state-by-date fixed effects. Plotted are coefficients on event time dummies from a regression which also includes date, county and state-by-date fixed effects and daily Covid-19 cases and deaths (in levels and logs) as controls. Regressions are weighted by county-level population in 2018 , and $95 \%$ confidence intervals. Standard errors are clustered two-way at the state and date level. Date 0 in event time is defined as the effective date of the stay-at-home order. Mobility outcomes derived from Unacast data. Per establishment revenue outcomes derived from Womply's panel of small businesses. 
Figure A12: Womply in event time: all sectors

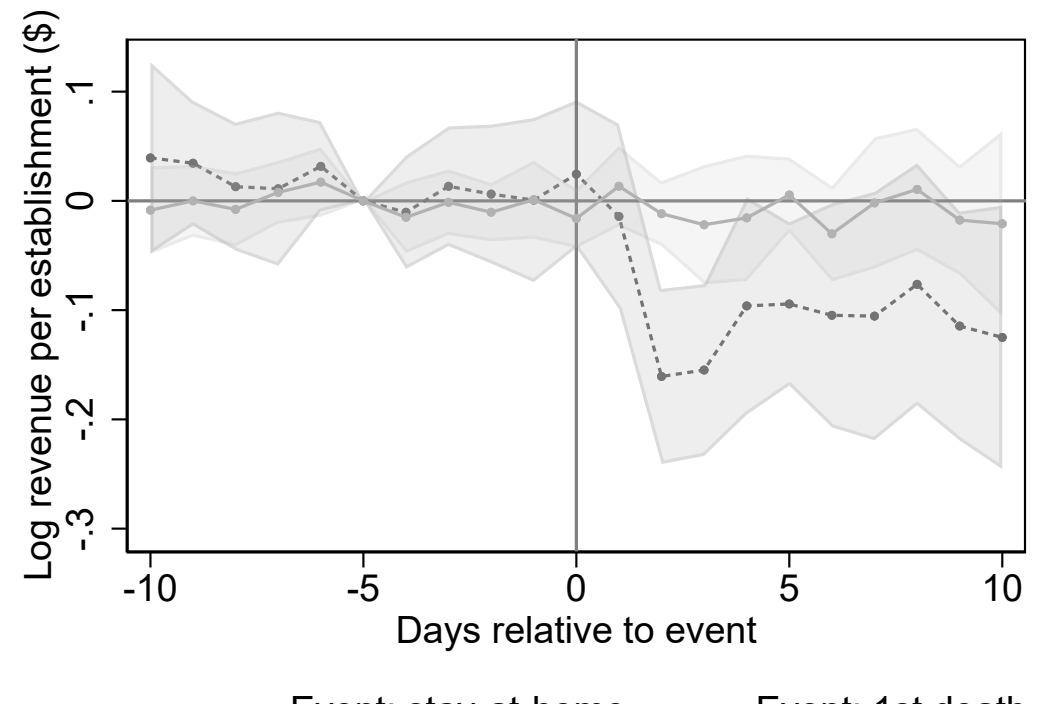

Event: stay-at-home —- Event: 1st death

Notes: Data at the county-day level. Plotted are coefficients on event time dummies from a regression which also includes date and county fixed effects and daily Covid-19 cases and deaths (in levels and logs) as controls. Regressions are weighted by county-level population in 2018, and 95\% confidence intervals. Standard errors are clustered two-way at the state and date level. Date 1 in event time is defined as the effective date of the stay-at-home order. Outcome is per establishment revenue derived from Womply's panel of small businesses.

Figure A13: Second Measure in event time: all sectors

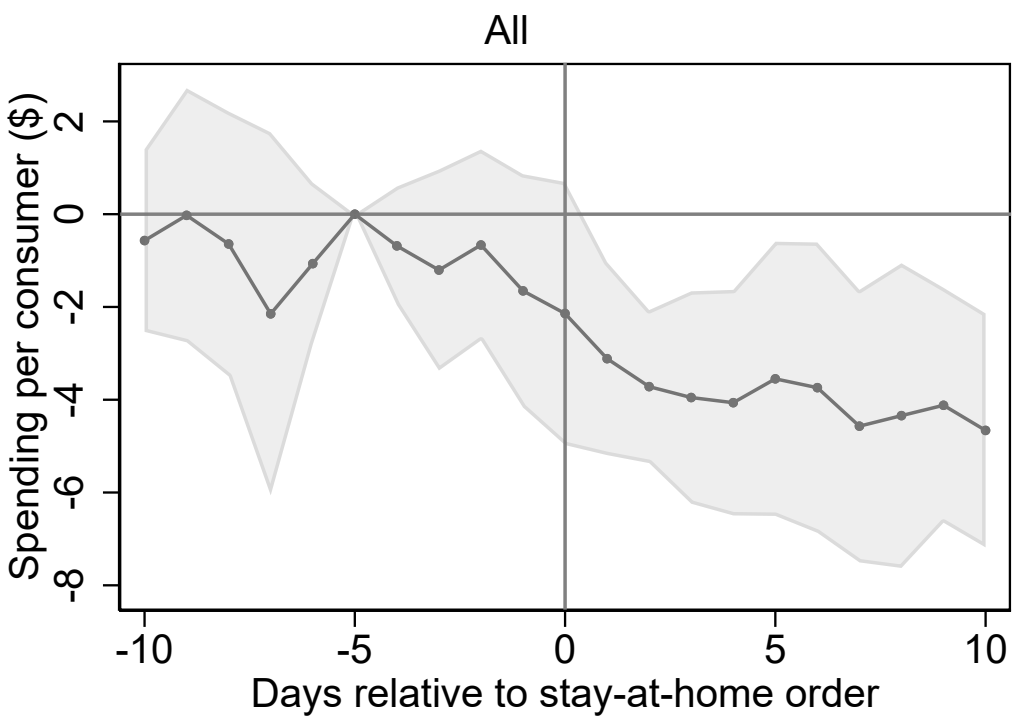

Notes: Data at the state-day level. Plotted are coefficients on event time dummies from a regression which also includes date and state fixed effects, weighted by state-level population in 2018, and 95\% confidence intervals. Standard errors are clustered two-way at the state and date level. Date 1 in event time is defined as the date $>50 \%$ of the state population covered was by a stay-at-home order. Only states with at least 5 days of post-event data are included (event time 0-4). Spending is scaled by the average number of consumers in the panel in each state over the first week of March. 


\section{Appendix Tables}

Table A1: Summary statistics: Womply

Summary Statistics: Daily Total Spending by County, Womply

March 1st - 7th 2020

\begin{tabular}{|c|c|c|c|c|c|}
\hline Sector & Avg. & Med. & 10th \% & 90th \% & Aggregated \\
\hline Arts and Entertainment Businesses & 1,790 & 0 & 0 & 2,383 & 12,782 Other \\
\hline Auto Sales Businesses & 13,889 & 0 & 0 & 29,920 & 81,228 Other \\
\hline Auto Services & 14,654 & 1,934 & 0 & 33,173 & 52,174 Other \\
\hline Educational Institutions & 20,710 & 0 & 0 & 23,262 & 163,082 Other \\
\hline Health and Beauty Businesses & 8,225 & 511 & 0 & 17,227 & 33,620 Other \\
\hline Healthcare and Medical Centers & 31,974 & 876 & 0 & 49,460 & 235,801 Other \\
\hline Local Services & 41,244 & 1,220 & 0 & 63,244 & 245,819 Other \\
\hline Lodging Places & 7,330 & 80 & 0 & 11,554 & 41,554 Other \\
\hline Online Businesses & 324 & 0 & 0 & 0 & 4,621 Other \\
\hline Parking Businesses & 1,686 & 0 & 0 & 0 & 28,946 Other \\
\hline Pet Services & 8,218 & 0 & 0 & 17,605 & 34,197 Other \\
\hline Professional Services & 39,542 & 795 & 0 & 46,221 & 271,455 Other \\
\hline Public Services and Government Places & 10,787 & 0 & 0 & 8,775 & 134,946 Other \\
\hline Religious Organizations & 451 & 0 & 0 & 200 & 4,527 Other \\
\hline Retail and Wholesale Businesses & 49,327 & 4,012 & 0 & 92,175 & 244,482 Other \\
\hline Sports and Recreation Places & 10,009 & 0 & 0 & 14,795 & 82,847 Other \\
\hline Transportation Businesses & 2,377 & 0 & 0 & 1,651 & 61,880 Other \\
\hline Bars and Lounges & 2,176 & 0 & 0 & 3,496 & 11,671 Restaurant \\
\hline Food and Beverage Shops & 16,316 & 1,275 & 0 & 28,983 & 66,492 Restaurant \\
\hline Quick Serve Food and Beverage Businesses & 4,430 & 30 & 0 & 9,241 & 18,377 Restaurant \\
\hline Restaurants & 32,494 & 3,813 & 0 & 60,698 & 150,336 Restaurant \\
\hline Overall & 317,952 & 31,395 & 2,109 & 598,829 & $1,290,957$ \\
\hline
\end{tabular}


Table A2: Summary statistics: Womply

Summary Statistics: Daily Per Business Spending, Womply

March 1st - 7th 2020

\begin{tabular}{|c|c|c|c|c|c|}
\hline Sector & Avg. & Med. & 10th \% & 90th \% & Aggregated \\
\hline Arts and Entertainment Businesses & 2,535 & 1,222 & 185 & 5,239 & 4,755 Other \\
\hline Auto Sales Businesses & 6,154 & 4,879 & 782 & 11,384 & 11,779 Other \\
\hline Auto Services & 1,887 & 1,816 & 410 & 3,218 & 1,473 Other \\
\hline Educational Institutions & 5,327 & 2,658 & 349 & 12,768 & 8,829 Other \\
\hline Health and Beauty Businesses & 905 & 842 & 425 & 1,406 & 646 Other \\
\hline Healthcare and Medical Centers & 2,658 & 2,119 & 300 & 4,392 & 5,754 Other \\
\hline Local Services & 4,492 & 3,080 & 559 & 8,283 & 10,461 Other \\
\hline Lodging Places & 3,915 & 2,357 & 468 & 8,778 & 5,386 Other \\
\hline Online Businesses & 3,842 & 1,110 & 67 & 8,235 & 9,366 Other \\
\hline Parking Businesses & 2,332 & 1,567 & 320 & 4,667 & 3,968 Other \\
\hline Pet Services & 4,237 & 3,829 & 882 & 7,454 & 3,501 Other \\
\hline Professional Services & 5,715 & 3,487 & 798 & 9,760 & 14,089 Other \\
\hline Public Services and Government Places & 4,542 & 2,065 & 272 & 7,622 & 10,194 Other \\
\hline Religious Organizations & 1,694 & 843 & 136 & 3,664 & 3,549 Other \\
\hline Retail and Wholesale Businesses & 2,801 & 2,347 & 786 & 4,631 & 3,578 Other \\
\hline Sports and Recreation Places & 3,433 & 1,862 & 431 & 6,165 & 10,112 Other \\
\hline Transportation Businesses & 2,072 & 561 & 135 & 2,330 & 21,750 Other \\
\hline Bars and Lounges & 1,625 & 1,088 & 241 & 3,584 & 1,980 Restaurant \\
\hline Food and Beverage Shops & 2,259 & 1,518 & 542 & 4,708 & 3,166 Restaurant \\
\hline Quick Serve Food and Beverage Businesses & 1,601 & 1,427 & 663 & 2,738 & 986 Restaurant \\
\hline Restaurants & 2,316 & 2,011 & 922 & 4,153 & 1,356 Restaurant \\
\hline Overall & 2,996 & 2,601 & 1,216 & 4,847 & 2,166 \\
\hline
\end{tabular}


Table A3: Summary statistics: Second Measure

Summary Statistics: Daily Total Spending by State, Second Measure

March 1st - 7th 2020

\begin{tabular}{|c|c|c|c|c|c|}
\hline Sector & Avg. & Med. & 10th \% & 90th \% & S.D. \\
\hline Accommodation \& Food Services & 233,787 & 100,833 & 0 & 593,404 & 381,738 \\
\hline Arts, Entertainment \& Recreation & 28,581 & 6,157 & 0 & 82,149 & 70,518 \\
\hline Construction & 203 & 0 & 0 & 505 & 704 \\
\hline Educational Services & 6,111 & 1,894 & 0 & 15,184 & 13,661 \\
\hline Finance \& Insurance & $1,090,551$ & 337,492 & 0 & $2,222,122$ & $2,126,674$ \\
\hline Food Delivery & 69,148 & 23,089 & 0 & 147,038 & 123,360 \\
\hline General/Wholesale Retail & 482,299 & 221,131 & 0 & $1,160,551$ & 760,045 \\
\hline Health Care \& Social Assistance & 12,123 & 1,767 & 0 & 23,519 & 61,133 \\
\hline Hotel Booking & 71,512 & 26,094 & 0 & 156,775 & 117,872 \\
\hline Information & 554,219 & 200,166 & 0 & $1,278,157$ & 951,774 \\
\hline Manufacturing & 16,905 & 6,461 & 0 & 45,099 & 26,985 \\
\hline Other Services (Except Public Administration) & 31,583 & 9,585 & 0 & 92,710 & 60,634 \\
\hline Professional, Scientific \& Technical Services & 11,075 & 3,546 & 0 & 30,535 & 21,087 \\
\hline Real Estate, Rental \& Leasing & 34,914 & 12,160 & 0 & 85,546 & 69,973 \\
\hline Retail Trade & $1,774,134$ & 642,942 & 0 & $4,288,429$ & $2,880,834$ \\
\hline Transportation & 128,606 & 45,076 & 0 & 326,387 & 220,888 \\
\hline Utilities & 5,492 & 143 & 0 & 5,573 & 26,097 \\
\hline Wholesale Trade & 3,322 & 566 & 0 & 8,897 & 7,516 \\
\hline Grocery Stores & 231,940 & 63,178 & 0 & 527,158 & 482,376 \\
\hline Pharmacies & 54,807 & 15,515 & 0 & 129,319 & 105,825 \\
\hline Amazon & 203,201 & 85,295 & 0 & 486,545 & 325,389 \\
\hline Overall & $4,072,265$ & $1,413,609$ & 0 & $8,839,463$ & $6,942,931$ \\
\hline
\end{tabular}

Notes: Data are state-level consumer spending totals from Second Measure's panel of consumer spending at large businesses (representing spending by roughly $1 \%$ of U.S. consumers). Second Measure data are divided into 21 categories. 17 of those categories are non-overlapping and based on NAICS code sectors. The remaining four: wholesale trade, grocery stores, pharmacies, and Amazon, are categories that we construct ourselves by hand-collecting firms and combining them into groups. For example, the Pharmacy sector contains CVS, Walgreens, Rite Aid, and a handful of smaller pharmacies. 
Table A4: Summary statistics: Second Measure

Summary Statistics: Daily Per Consumer Spending, Second Measure

March 1st - 7th 2020

\begin{tabular}{lccccc}
\hline \multicolumn{1}{c}{ Sector } & Avg. & Med. & 10th \% & 90th \% & S.D. \\
\hline Accommodation \& Food Services & 3.71 & 3.64 & 2.52 & 4.82 & 0.84 \\
Arts, Entertainment \& Recreation & 0.45 & 0.30 & 0.16 & 0.99 & 0.46 \\
Construction & 0.00 & 0.00 & 0.00 & 0.01 & 0.01 \\
Educational Services & 0.10 & 0.07 & 0.04 & 0.21 & 0.08 \\
Finance \& Insurance & 17.32 & 15.49 & 11.85 & 25.89 & 5.71 \\
Food Delivery & 1.10 & 1.01 & 0.76 & 1.51 & 0.34 \\
General/Wholesale Retail & 7.66 & 7.59 & 5.27 & 9.63 & 1.91 \\
Health Care \& Social Assistance & 0.19 & 0.10 & 0.05 & 0.37 & 0.32 \\
Hotel Booking & 1.14 & 1.13 & 0.89 & 1.37 & 0.20 \\
Information & 8.80 & 8.31 & 6.73 & 11.09 & 2.21 \\
Manufacturing & 0.27 & 0.26 & 0.16 & 0.36 & 0.11 \\
Other Services (Except Public Administration) & 0.50 & 0.38 & 0.28 & 0.92 & 0.35 \\
Professional, Scientific \& Technical Services & 0.18 & 0.14 & 0.10 & 0.35 & 0.19 \\
Real Estate, Rental \& Leasing & 0.55 & 0.46 & 0.30 & 0.98 & 0.30 \\
Retail Trade & 28.18 & 27.81 & 24.01 & 32.60 & 3.55 \\
Transportation & 2.04 & 1.92 & 1.42 & 2.79 & 0.57 \\
Utilities & 0.09 & 0.01 & 0.00 & 0.21 & 0.25 \\
Wholesale Trade & 0.05 & 0.04 & 0.01 & 0.10 & 0.07 \\
Grocery Stores & 3.68 & 3.36 & 1.29 & 6.66 & 1.95 \\
Pharmacies & 0.87 & 0.75 & 0.51 & 1.56 & 0.37 \\
Amazon & 3.23 & 3.16 & 2.34 & 4.08 & 0.71 \\
Overall & 64.68 & 63.18 & 53.83 & 77.55 & 9.44 \\
\hline & & & & & \\
\hline
\end{tabular}

Notes: Per consumer spending numbers divide Second Measure's total spending per category by the average number of consumers reported daily in the Second Measure panel between March 1st and March 7th. Second Measure data are divided into 21 categories. 17 of those categories are non-overlapping and based on NAICS code sectors. The remaining four: wholesale trade, grocery stores, pharmacies, and Amazon, are categories that we construct ourselves by hand-collecting firms and combining them into groups. For example, the Pharmacy sector contains CVS, Walgreens, Rite Aid, and a handful of smaller pharmacies. 